\title{
Composite adsorption of Copper ions by iron oxide, organic matter and clay mineral complexes in sediments: antagonistic effect of organic matter
}

\author{
Leng Liu1 ${ }^{1,2,3}$, Yi-Chuan Fang ${ }^{1,2,3}$ and Xiao-Long Sun ${ }^{1,2,3 *}$
}

1Yunnan Key Laboratory of Plateau Wetland Conservation, Restoration and Ecological Services, College of Wetlands, Southwest Forestry University, Kunming 650224, China.

2 National Plateau Wetlands Research Center, Southwest Forestry University, Kunming 650224, China. 3 National Wetland Ecosystem Fixed Research Station of Yunnan Dianchi, Southwest Forestry University, Kunming 650224, China.

*Correspondence: Xiao-Long Sun. sunx196@gmail.com
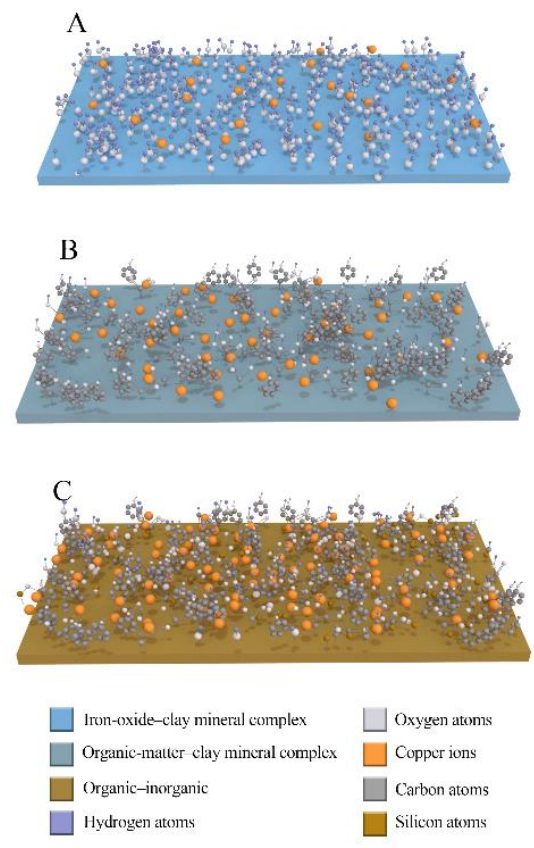

Isothermal adsorption curves of three kinds of complexes in the sediments. Group A ( $\mathrm{a}$, in black) is the ad-sorption isothermal curve of the iron-oxide-clay mineral complex. Group B (b, in red) is the adsorption isothermal curve of the organic-clay mineral complex. Group C (c, in blue) is the adsorption isothermal curve of the organic-inorganic comple.

\begin{abstract}
The combination of organic matter, iron oxide, and clay minerals is of great significance for the adsorption of copper ions $(\mathrm{Cu})$. The purpose of this study is to explore the characteristics of $\mathrm{Cu}$ adsorption and laws governing $\mathrm{Cu}$ complexation to organic-inorganic, organic-clay mineral, and iron-oxide-clay mineral complexes in the sediments in the estuary of plateau fault and sinking lake__Dianchi Lake. In this study, $\mathrm{Cu}$ adsorption tests were performed on the three complexes, in order to study the kinetic behavior of adsorption, Langmuir and Freundlich isotherm models were used. The samples before and after adsorption were characterized via scanning electron microscope (SEM), Fourier infrared spectroscopy (FTIR), and X-ray diffraction (XRD). Our results show that, the Freundlich isotherm models model was able to describe adsorbent behavior in comparison to the Langmuir models. During the $\mathrm{Cu}$ adsorption process, the iron-oxide-clay mineral complex is able to adsorb $\mathrm{Cu}$, via coordination exchange, through the $-\mathrm{OH}$ contained therein. Organic-matter-clay mineral complexes bonded to the surfaces of clay minerals by replacing the hydroxyl groups with functional groups (carboxyl groups or phenolic hydroxyl groups) contained in the organic matter. Organic-inorganic composites then adsorbed $\mathrm{Cu}$ through the coordination
\end{abstract}


exchange of -OH in the polar functional groups of alcohols, phenols, and carboxylic acids. The adsorption capacity of $\mathrm{Cu}$ in these three sediment complexes was observed to have the following order: organic-inorganic complex > organic-matter-clay mineral complex > iron-oxide-clay mineral complex. The semi-quantitative analysis results of Fourier Infrared Spectroscopy show that the organic matter (changes in the peak area of functional groups such as carboxyl groups) in the organicinorganic composite material has an important effect on the amount of copper ions adsorbed by clay minerals.

Keywords: metal adsorption; soil organic matter; iron oxide; Semi-quantitative analysis method ; antagonistic effect; DCB extraction

\section{1. introduction}

Heavy metal pollution is of great significance for the environment and human health. Heavy metals in aquatic environments cannot be decomposed via natural processes. Consequently, heavy metals often become enriched in sediments, due to the action of organisms, or in other compounds. In this way, sediments have become carriers and potential sources of heavy metals in the aquatic environment. The combination of sediments and heavy metals with different structures and forms will affect the activation potential and bioavailability of the sediments as well as the heavy metal toxicity. Therefore, sediments also play an important role in the processes of metal migration and transformation ${ }^{[1]}$. At the same time, the deposition and migration of heavy metals in the river-lake transition area will be affected by the superposition of the two constituent waterbodies, namely rivers and lakes. Moreover, the region features a wide range, strong dynamics, and complex hydrodynamic conditions, which together make the migration and transformation of pollutants very complex.

River inlets are located in the transition area between a river and a lake. The river inlet is the area where the energy flow and material circulation between the river and the lake are strongest, which are strongly influenced by many factors of a natural, physical, chemical, or biological nature. Furthermore, estuary circulation, the redistribution of river sediment (input, resuspension, exchange with the neighboring environment, etc.), salinity, geological disturbances, redox, earthquakes, dissolved oxygen, and the $\mathrm{pH}$ of waterbodies can all affect the mobility and spatial distribution of metals, including through dissolution, deposition, and diffusion [2]. Pollutants can easily accumulate in river inlets, and the forms of metal deposition at the estuary show diversification ${ }^{[3]}$.

Sediments are mainly composed of minerals (erie, kaolin, and montmorillonite). A combination of metal oxides (iron oxide, aluminum oxide, and manganese oxide) and organic matter (mainly humic acid and tannic acid) produces flocculent aggregates on the surface of mineral particles [2]. Metal-hydrated oxides and organic matter have surface hydroxyl groups that can adsorb metal ions, and clay minerals feature permanent structural charges. Metal-hydrated oxides, organic matter, and clay minerals play indispensable roles in the adsorption processes of heavy metal pollution ${ }^{[4,5]}$. Due to the importance of a single metal $(\mathrm{Cu})$, the adsorption of heavy metals and clay minerals, the co-precipitation of hydrated oxides of iron and manganese, and the combination of organic molecular complexes or silicates and other primary minerals in the crystal lattice have become important methods for fixation and removal of heavy metals in the water environment [6].

At present, there are many studies on the adsorption of single components and organic and inorganic pollutants but relatively few on the adsorption of sediment complexes and pollutants, organic matter, metal oxides, etc. Therefore, in this study, we sought to further explore the adsorption mechanisms of multi-component interactions and improve the theoretical understanding of adsorption in multi-component-complex systems. The crustal movement produced stratigraphic faults and subsidences in the Dianchi Lake. Dianchi Lake is the largest rifted freshwater lake on the Yunnan Plateau. It plays an 
extremely important role in the economy, culture and politics of the Lake District. In the present study, we take the sediments of the estuary of Dianchi Lake as our research object. Organic-matter-clay minerals, iron-oxide-clay minerals, and organic-inorganic composites were prepared from the sediments, and their effects on the adsorption capacities metal ions were investigated. What is important is that, the difference in adsorption mechanisms between three clays was inspected using advanced analysis techniques including scanning electron microscopy (SEM), fourier transform infrared spectroscopy (FTIR) and $\mathrm{X}$-ray diffraction (XRD) analysis. We also analyze equilibrium data through nonlinear regression using the Langmuir and Freundlich isotherm models and explore the adsorption mechanism underlying the multi-component interactions of organic matter, iron oxides, and clay minerals. Analyzing the mechanism of sediment adsorption of heavy metals at the mouth of the lake will help determine the mechanism by which heavy metals are absorbed in wetland sediments, thus providing the basic data for mastering the laws of heavy metal ion migration and transformation in highland lakes and assisting in the establishment of engineering and technical schemes for heavy metal control in lakes.

\section{Materials and Methods}

\subsection{Collection of Soil Samples}

Dianchi, the largest plateau and freshwater lake in Yunnan Province, is located in the transition area between the river and lake and represents the most intense area of energy flow and material circulation between the river and lake. At the same time, the estuary is also a place of abundant biodiversity within the lake[2]. Thus, the area is easily enriched by many factors, such as of a physical, chemical, or biological nature, leading to the diversification of metal-deposit forms at the estuary. The sediment samples used in this experiment were collected from eight rivers on the east and south banks of Yuchi in Kunming, Yunnan Province: Chai he (CH), Dong da he (DD), Company Trench (GS), Broad Spectrum Trench (GP), Fish River (LY), Lao bao River (LB), New River (XH), and Silt River $(\mathrm{YN})$. Dianchi Lake is a plateau faulted and subsided lake, with the topography characteristics of five-level terraces high in the northeast and low in the southwest. Among them, LB, GP, and GS are located in Zone II where the content of kaolinite (average value is $45.6 \%$ ) is relatively high, and $\mathrm{LY}, \mathrm{YN}, \mathrm{CH}, \mathrm{XH}$ and $\mathrm{DD}$ are located where the content of illite (average value is $41 \%$ ) is relatively high The $\mathrm{V}$ area. The sediment from the top 10 $\mathrm{cm}$ of surface was collected using a fixed-depth peat drill and sealed and stored in a selfsealing bag. We air-dried the sample in a cool, ventilated area, removed impurities, and placed the sample in a sealed pocket for backup. A sample point diagram is shown in Figure 1. 


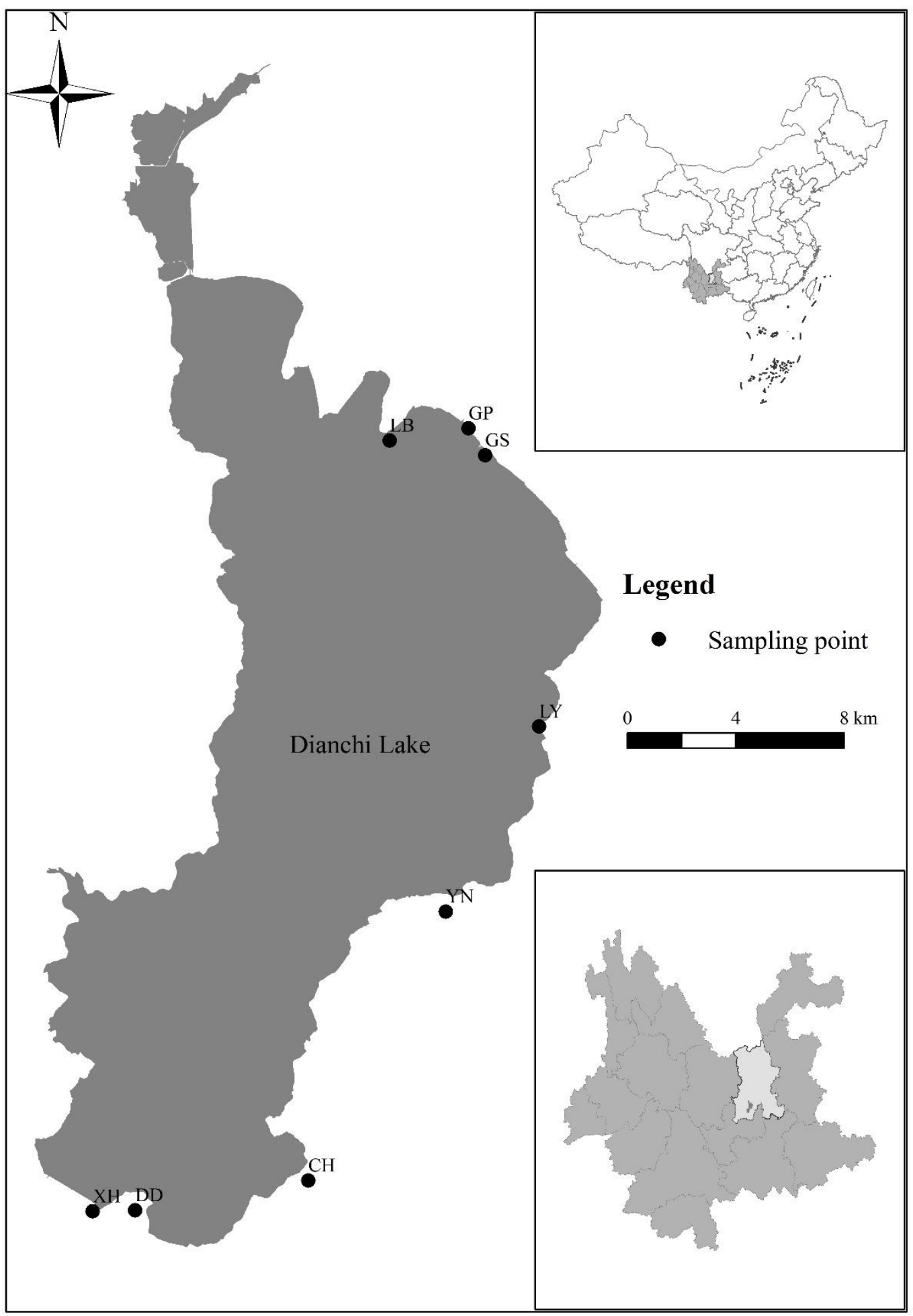

Figure 1. Distribution of sampling points.

\subsection{Basic Physical and Chemical Properties}

The $\mathrm{pH}$ ratio of 1:2.5 was measured using a corrected acidity meter [7]. Total organic carbon (TOC) was measured using the dry combustion method and a total organic carbon analyzer ${ }^{[8]}$. The cation exchange capacity in sediment was determined via spectrophotography using a hexamine cobalt trichloride solution ${ }^{[9]}$. Iron oxide was measured using dithionitrate-bicarbonate (DCB) ${ }^{[10]}$. 
The basic physical and chemical properties of the soil samples according to their sampling location are shown in Table 1.

Table 1. Basic physical and chemical properties of the tested soil samples.

\begin{tabular}{ccccc}
\hline $\begin{array}{c}\text { Sampling Lo- } \\
\text { cation }\end{array}$ & $\begin{array}{c}\text { Free Iron Oxide } \\
\mathbf{m g} / \mathbf{k g}\end{array}$ & $\mathbf{p H}$ & $\begin{array}{c}\mathbf{C E C} \\
\mathbf{c m o l} / \mathbf{k g}\end{array}$ & $\begin{array}{c}\text { SOM } \\
\mathbf{g} / \mathbf{k g}\end{array}$ \\
\hline CH & 35.51 & 8.49 & 31.27 & 27.83 \\
DD & 26.55 & 7.97 & 32.25 & 50.12 \\
GS & 30.73 & 8.25 & 45.36 & 59.33 \\
GP & 35.23 & 8.02 & 56.87 & 52.33 \\
LY & 49.59 & 8.02 & 52.33 & 43.64 \\
LB & 28.27 & 7.91 & 20.77 & 38.75 \\
XH & 8.98 & 8.35 & 18.71 & 35.97 \\
YN & 85.05 & 8.06 & 57.92 & 23.61 \\
\hline
\end{tabular}

\subsection{Preparation of the Complex}

The iron-oxide-clay mineral complex (Group A) was prepared using oxidation with $30 \%$ hydrogen peroxide $\left(\mathrm{H}_{2} \mathrm{O}_{2}\right)$ to remove organic matter ${ }^{[11,12]}$. In a $500 \mathrm{~mL}$ beaker, $100 \mathrm{~g}$ of the sediment was saturated with nano-pure water and placed in a water bath to reach about $90^{\circ} \mathrm{C} . \mathrm{H}_{2} \mathrm{O}_{2}(30 \%)$ was added to the saturated precipitate in $5 \mathrm{~mL}$ increments, and stirred as the reaction occurred, adding a total of $60 \mathrm{~mL} \mathrm{H} 2 \mathrm{O} 2$. After almost all the liquid has evaporated, delete the beaker from the heat and cool it down. Then complete the process a second time to delete more organic matter, wash three times, and homoge-nize as previously described.

Preparation of the organic-clay mineral complex (Group B) used the citric acid disulfate bicarbonate (DCB) method to remove free iron oxides [13-15]. Weigh $0.500 \mathrm{~g}$ of air-dried soil sample that has passed through a $0.25 \mathrm{~mm}$ standard sieves and place it in a $50 \mathrm{~mL}$ centrifuge tube. Add $20 \mathrm{~mL}$ of $1 \mathrm{~mol} / \mathrm{L}$ sodium citrate solution and $2.5 \mathrm{~mL}$ of $1 \mathrm{~mol} / \mathrm{L}$ sodium bicarbonate solution. Heat to $80^{\circ} \mathrm{C}$ in a water bath, and add sodium dichromate $0.5 \mathrm{~g}$, keep stirring for $15 \mathrm{~min}$. After the solution in the centrifuge tube has cooled, add $5 \mathrm{~mL}$ of saturated sodium chloride solution to the centrifuge tube, mix well, and pour the supernatant into a $250 \mathrm{~mL}$ volumetric flask. Repeating the above treatment for 2 times. Wash the residue in the centrifuge tube with $1 \mathrm{mo} 1 / \mathrm{L}$ sodium chloride solution, centrifuge at $3500 \mathrm{r} / \mathrm{min}$ for $5 \mathrm{~min}$, repeat the above treatment 3 times, and place the remaining soil sample in a freeze dryer for freeze drying.

We used ultrasonic dispersion to extract organic-inorganic complexes (Group C) [16]. Weigh $30 \mathrm{~g}$ of air-dried soil through a $1 \mathrm{~mm}$ sieve into a $100 \mathrm{~mL}$ beaker, add $50 \mathrm{ml}$ of water, stir for $2 \mathrm{~min}$, and place in an ultrasonic cleaning tank at $20^{\circ} \mathrm{C}$ for $30 \mathrm{~min}$ ultrasonic dispersion. Use a glass rod to carefully remove $50 \mathrm{~mL}$ of biological residues. The washing sequence is passed through $0.25 \mathrm{~mm}$ and $0.05 \mathrm{~mm}$ sieves, and the lower liquid is received with an evaporating dish. The evaporating dish containing the composite suspension is placed on a water bath and steamed to near dryness, dried to constant weight at $40^{\circ} \mathrm{C}$, and weighed after cooling at room temperature.

\subsection{Fitting of Adsorption Isotherms}

Deposits of $0.2 \mathrm{~g}$ were weighed in a $50 \mathrm{~mL}$ plastic centrifuge tube containing $20 \mathrm{~mL}$ $\mathrm{NaNO}_{3}\left(0.01 \mathrm{~mol} \mathrm{~L}^{-1}\right.$ ion strength) for 2, 5, 10, 30, 75, and $150 \mathrm{mg} \mathrm{L}^{-1}$ of $\mathrm{Cu}$ using 1 and 0.1 mol L $\mathrm{L}^{-1}$ of sodium hydroxide and nitric acid solution adjusted to $\mathrm{pH} 6$, followed oscillation on a shaker at $300 \mathrm{rmin}^{-1}$ for $24 \mathrm{~h}$ after filtering of the liquid through a $0.45 \mu \mathrm{m}$ membrane filter. ICP-OES was used to characterize the solution contents. The final adsorption was calculated using the following formula [17]:

$$
Q e=\frac{C o-C e}{m} * V
$$


where Qe is the adsorption capacity, $\mathrm{mg} \mathrm{L}^{-1}$; Co is the initial concentration of heavy metal in the solution, $\mathrm{mg} \mathrm{L}^{-1}$; Ce is the concentration of heavy metal in the solution after reaching adsorption equilibrium, $\mathrm{mg} \mathrm{L}^{-1}$; Vis the solution volume, $\mathrm{L}$; and $\mathrm{M}$ is the sediment quality, g.

The Freundlich model and Langmuir models were used for least-squares-regression fitting of the adsorption experimental data ${ }^{[11]}$.

\subsection{Characterization}

\subsection{1. $X$-ray diffraction $(X R D)$}

The instrument model is UltimaIV X-ray $\mathrm{Cu}$ Ka radiation diffractometer, wavelength $0.15406 \mathrm{~nm}$, voltage $40 \mathrm{KV}$, current $40 \mathrm{~mA}$, scanning speed $2^{\circ} / \mathrm{min}$, scanning range $10-90^{\circ}$.

\subsubsection{Fourier infrared spectroscopy}

The instrument model is Bruker MPA \& Tensor 27. Take 1 2 mg powder sample and $200 \mathrm{mg}$ pure $\mathrm{KBr}$ and grind it evenly, place it in a mold, press it into a transparent sheet on a hydraulic press, and put the sample into an infrared spectrometer for testing. Wavenumber range $4000 \sim 400 \mathrm{~cm}^{-1}$, scanning times 32 , resolution $4 \mathrm{~cm}^{-1}$.

\subsubsection{Curve fitting of FT-IR spectra}

In order to obtain quantitative information, the FT-IR spectrum of each sample is divided into several spectral regions representing peaks $\left(796 \mathrm{~cm}^{-1} 、 3446 \mathrm{~cm}^{-1} 、 3622 \mathrm{~cm}\right.$ 1、 $3697 \mathrm{~cm}^{-1}$ ), and curve fitting is performed on each region according to the principle of second derivative.

$796 \mathrm{~cm}^{-1}$ : - $\mathrm{CH}$ derived from aliphatic or aromatic compounds.

$4000-3000 \mathrm{~cm}^{-1},\left(3446 \mathrm{~cm}^{-1} 、 3622 \mathrm{~cm}^{-1} 、 3697 \mathrm{~cm}^{-1}\right)$ : Derived from most of $-\mathrm{OH}$ in alcohols, phenols and carboxylic acids.

\subsubsection{Scanning Electron Microscope (SEM)}

The instrument model is ZEISS Gemini 300, the electronic light path is the electron beam in the lens barrel without cross light path, the acceleration voltage is $0.02-30 \mathrm{kV}$, and the $10 \mathrm{~V}$ step is continuously adjustable. Probe beam $3 \mathrm{pA}-20 \mathrm{nA}$, magnification $12 \mathrm{x}-$ $2000000 x$, objective lens is electromagnetic/electrostatic compound lens, sample chamber size is $365 \mathrm{~mm} \times 275 \mathrm{~mm}$, sample stage stroke $X=125 \mathrm{~mm} ; Y=125 \mathrm{~mm} ; Z=50 \mathrm{~mm}$; T = $10^{\circ}-90^{\circ} ; \mathrm{R}=360^{\circ}$ (continuously adjustable), image acquisition up to $32 \mathrm{k} \times 24 \mathrm{k}$.

\subsection{Data Processing}

All data were analyzed in SPSS 26, and the plots were mainly constructed using Origin 9.0 and Excel.

\section{Results}

3.1. Three Sets of Complex Adsorption Iso-Temperature Curves 

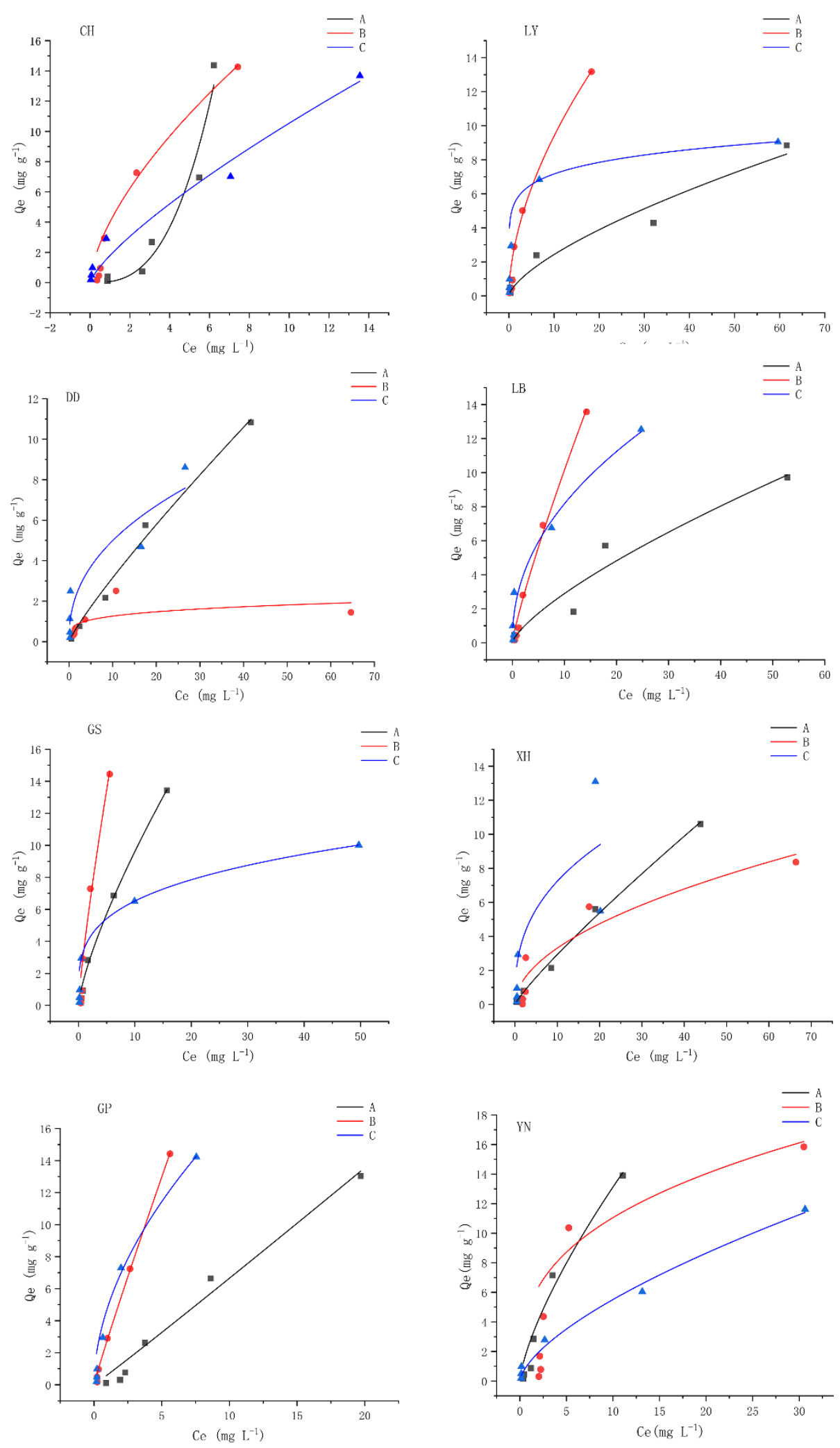

Figure 2. Isothermal adsorption curves of three kinds of complexes in the sediments. Group A (a, in black) is the adsorption isothermal curve of the iron-oxide-clay mineral complex. Group B (b, in red) is the adsorption isothermal curve of the organic-clay mineral complex. Group C (c, in blue) is the adsorption isothermal curve of the organic-inorganic complex. Lines represent the Freundlich model simulations

Table 2. Freundlich isothermal model and Langmuir isothermal model parameters. 


\begin{tabular}{|c|c|c|c|c|c|c|c|}
\hline \multirow{2}{*}{$\begin{array}{c}\text { Sampling } \\
\text { Site }\end{array}$} & \multirow[t]{2}{*}{ Group number } & \multicolumn{3}{|c|}{ Freundlich model } & \multicolumn{3}{|c|}{ Langmuir model } \\
\hline & & $K_{f}$ & $1 / \mathrm{n}$ & $\mathbf{R}^{2}$ & $Q_{\max }$ & $\mathrm{K}_{\mathrm{L}}$ & $\mathbf{R}^{2}$ \\
\hline \multirow[t]{3}{*}{$\mathrm{CH}$} & A & 0.07 & 2.88 & 0.9956 & $2.92898 \mathrm{E} 6$ & $6.21841 \mathrm{E}-7$ & 0.92616 \\
\hline & $\mathrm{B}$ & 4.01 & 0.64 & 0.99698 & 26.38 & 0.16 & 0.99831 \\
\hline & $\mathrm{C}$ & 1.79 & 0.77 & 0.99375 & 55.11 & 0.02 & 0.99084 \\
\hline \multirow[t]{3}{*}{ DD } & $\mathrm{A}$ & 0.42 & 0.87 & 0.9995 & 43.686 & 0.008 & 0.99967 \\
\hline & $\mathrm{B}$ & 0.75 & 0.23 & 0.99928 & 2.06 & 0.37 & 0.99961 \\
\hline & $\mathrm{C}$ & 1.86 & 0.43 & 0.99332 & 7.12 & 0.80 & 0.78554 \\
\hline \multirow[t]{3}{*}{ GS } & $\mathrm{A}$ & 1.71 & 0.75 & 0.99851 & 33.331 & 0.043 & 0.99892 \\
\hline & $\mathrm{B}$ & 3.57 & 0.82 & 0.99635 & 42.62 & 0.09 & 0.99721 \\
\hline & $\mathrm{C}$ & 3.52 & 0.27 & 0.99993 & 10.66 & 0.21 & 0.99904 \\
\hline \multirow[t]{3}{*}{ GP } & $\mathrm{A}$ & 0.63 & 1.03 & 0.99453 & 219.972 & 0.003 & 0.99457 \\
\hline & B & 2.84 & 0.94 & 0.99975 & 131.44 & 0.02 & 0.99979 \\
\hline & $\mathrm{C}$ & 4.82 & 0.54 & 0.99894 & 21.82 & 0.25 & 0.99978 \\
\hline \multirow[t]{3}{*}{ LY } & A & 0.51 & 0.68 & 0.9993 & 46.252 & 0.004 & 0.99898 \\
\hline & B & 2.56 & 0.65 & 0.99751 & 19.28 & 0.12 & 0.99882 \\
\hline & $\mathrm{C}$ & 5.29 & 0.13 & 0.99987 & 9.22 & 0.49 & 0.9999 \\
\hline \multirow[t]{3}{*}{ LB } & A & 0.53 & 0.74 & 0.99815 & 23.506 & 0.014 & 0.99827 \\
\hline & B & 1.42 & 0.85 & 0.99683 & 46.30 & 0.03 & 0.99808 \\
\hline & $\mathrm{C}$ & 2.83 & 0.46 & 0.99869 & 17.38 & 0.10 & 0.99507 \\
\hline \multirow[t]{3}{*}{$\mathrm{XH}$} & A & 0.39 & 0.88 & 0.9997 & 45.603 & 0.007 & 0.9998 \\
\hline & B & 1.01 & 0.52 & 0.99799 & 10.39 & 0.07 & 0.999 \\
\hline & $\mathrm{C}$ & 3.07 & 0.37 & 0.94052 & 10.05 & 0.61 & 0.94166 \\
\hline \multirow[t]{3}{*}{ YN } & A & 2.52 & 0.72 & 0.99237 & 28.597 & 0.086 & 0.99581 \\
\hline & B & 5.02 & 0.34 & 0.9735 & 19.40 & 0.16 & 0.9844 \\
\hline & C & 1.24 & 0.65 & 0.99916 & 24.64 & 0.03 & 0.99748 \\
\hline
\end{tabular}

The Langmuir isotherm adsorption equation indicates that the adsorption of $\mathrm{Cu}$ by the composite is monolayer adsorption, with uniform adsorption of $\mathrm{Cu}$ on the composite surface. The Freundlich isotherm adsorption equation shows that the adsorption of $\mathrm{Cu}$ by the complex occurred by multi-molecular layer adsorption. Comparing the correlation coefficients $\left(\mathrm{R}^{2}\right)$, the $\mathrm{R}^{2}$ fitting coefficient of the Freundlich isotherm adsorption equation for $\mathrm{Cu}$ adsorption was better than that of the Langmuir isotherm adsorption equation. In Freundlich model, $\mathrm{K}_{\mathrm{f}}$ and $1 / \mathrm{n}$ are constants related to the capacity and favorability of adsorption, respectively ${ }^{[18]}$. In temperature adsorption equations, such as those used in the Freundlich model, the $1 / \mathrm{n}$ parameter reflects the affinity of the adsorbent to adsorption; the smaller the value, the greater the affinity. The parameter $1 / \mathrm{n}$ for Group A, Group B, and Group C respectively varied from 0.68 to $2.88,0.23$ to $0.94,0.13$ to 0.77 , Group B and Group C values $1 / \mathrm{n}<1$ confirms that the adsorptions of Group B, and Group C for Cu ions are favorable adsorption. The affinity is the weakest for Group C samples, which are generally conducive to adsorption. $\mathrm{K}_{\mathrm{f}}$ reflects the adsorption capacity of the adsorbent to adsorption; the greater the value, the greater the adsorption capacity. According to Table 2 , it can be seen that the adsorption capacity of zone II sediments dominated by kaolinite to copper ions is stronger than that of zone $\mathrm{V}$ sediments dominated by illite. According to Table 2, we can also know the parameter $\mathrm{K}_{\mathrm{f}}$ for Group A, Group B, and Group C respectively varied from 0.07 to $2.52,0.75$ to $5.02,1.24$ to 5.29 . The results showed that the adsorption capacity of $\mathrm{Cu}$ in group $\mathrm{C}$ was the largest, that in group $\mathrm{B}$ was the second, and that in group $\mathrm{C}$ was the worst. $R_{L}$ is a dimensionless constant obtained from the Langmuir isotherm model. $R_{L}$ values indicate the shape of isotherm: (1) unfavourable $\left(R_{L}>1\right)$, (2) linear $\left(R_{L}=1\right)$, (3) favourable $0<R_{L}<1$, and (4) irreversible $\left(R_{L}=0\right)$. The $R_{L}$ values for $C u$ (II) following adsorption by Group A, Group B, and Group C were in the range $0<R_{L}<1$. This indicates that the adsorption of metal ions was favourable.

Overall, for the results of this equation reveal that $C$ has the strongest adsorption capacity. These results indicate that the adsorption ability of Group A presented the weakest adsorption capacity. Group C presented the strongest adsorption capacity. 


\subsection{Adsorption Studies}

\subsubsection{Comparison of Group A before and after $\mathrm{Cu}$ Adsorption}

There were significant changes in the FTIR spectrum of the iron-oxide-clay mineral complex after interaction with $\mathrm{Cu}$ ions (Figure 3). After the adsorption of copper in Group $\mathrm{A}$, the intramolecular hydrogen bond - $\mathrm{OH}$ stretching vibration peak and carboxyl bending vibration peak (3446.64-3442.78 $\mathrm{cm}^{-1}$ ) and alcohol and phenol -OH stretching vibration peaks (3650-3620 $\mathrm{cm}^{-1}$ ) shifted. Moreover, the absorption peak disappeared, along with other changes. The results show that $-\mathrm{OH}$ was complexed or coordinated with $\mathrm{Cu}$. The absorption peak of ammonium salt compounds at $2380.40-2308.69 \mathrm{~cm}^{-1}$ disappeared, indicating that these salt compounds complexed or coordinated with $\mathrm{Cu}$. The bending vibration of the carboxyl group, with the signal near $1430 \mathrm{~cm}^{-1}$, has either red-shifted or disappeared, and along with the movement of 2311.92, 1430.23, and $690.48 \mathrm{~cm}^{-1}$, indicates that quartz was involved in the process of $\mathrm{Cu}$ adsorption. Moreover, the stretching vibration peak of $\mathrm{Si}-\mathrm{O}-\mathrm{Mg}$ at about $532 \mathrm{~cm}^{-1}$ and the stretching vibration peak of $\mathrm{Si}-\mathrm{O}-\mathrm{Al}$ at about $538 \mathrm{~cm}^{-1}$ were blue-shifted, indicating that $\mathrm{Cu}$ entered the mineral and underwent complexation. The Si-O bending vibration peak around $470 \mathrm{~cm}^{-1}$ indicates that surface complexation or coordination occurred. 

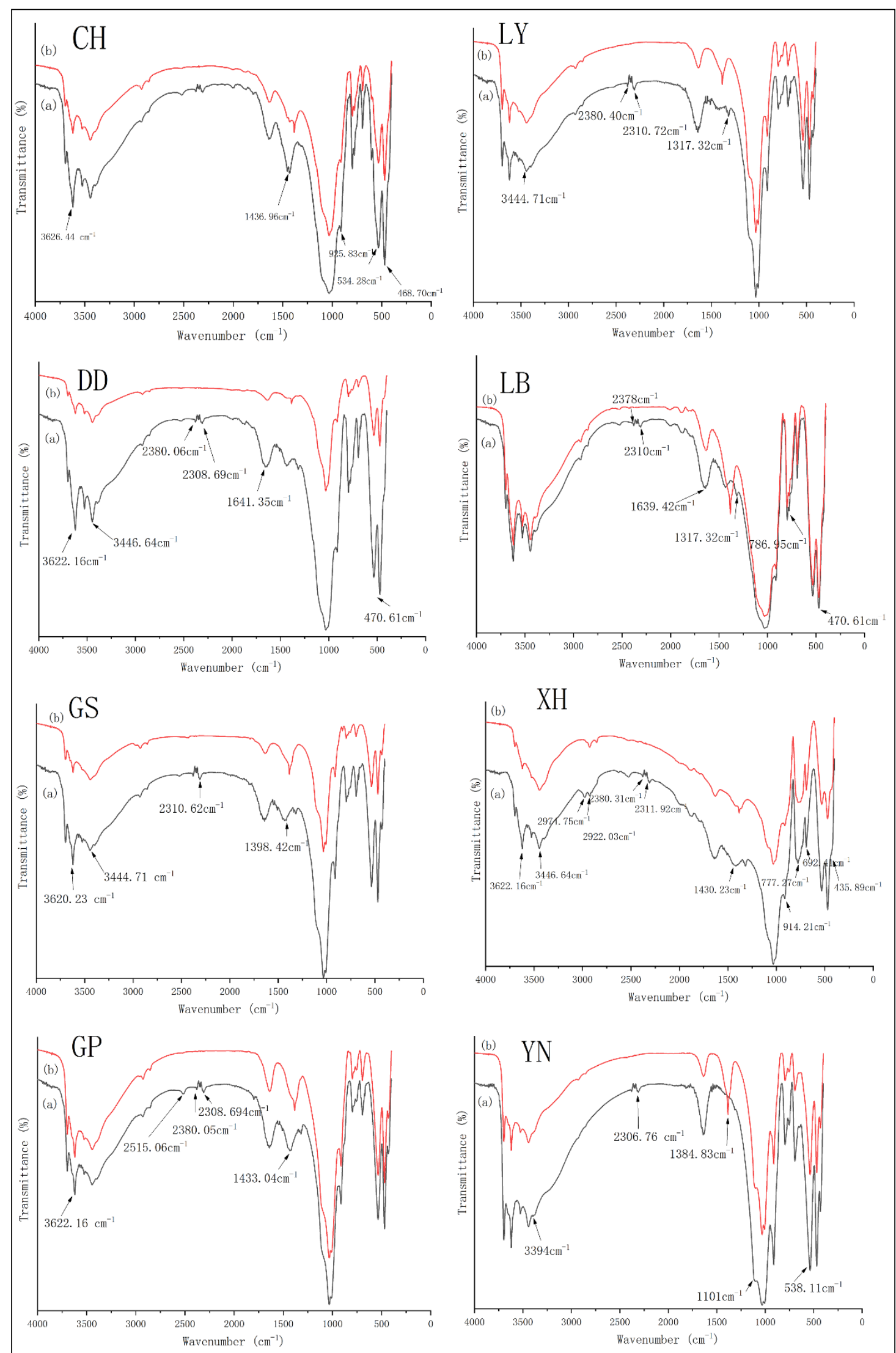

Figure 3. FTIR spectra of $\mathrm{Cu}(\mathrm{a})$ before and (b) after adsorption into the iron-oxide-clay mineral complex.

Therefore, the adsorption of $\mathrm{Cu}$ by A occurred mainly through $-\mathrm{OH}$, as observed in the stretching vibration peaks of the alcohols and phenols, the $-\mathrm{OH}$ stretching vibration peak of intramolecular hydrogen bonding, and the bending vibration peak of the carboxyl 
group, enabling complexation or coordination with $\mathrm{Cu}$. In addition, silicide participated in the adsorption process.

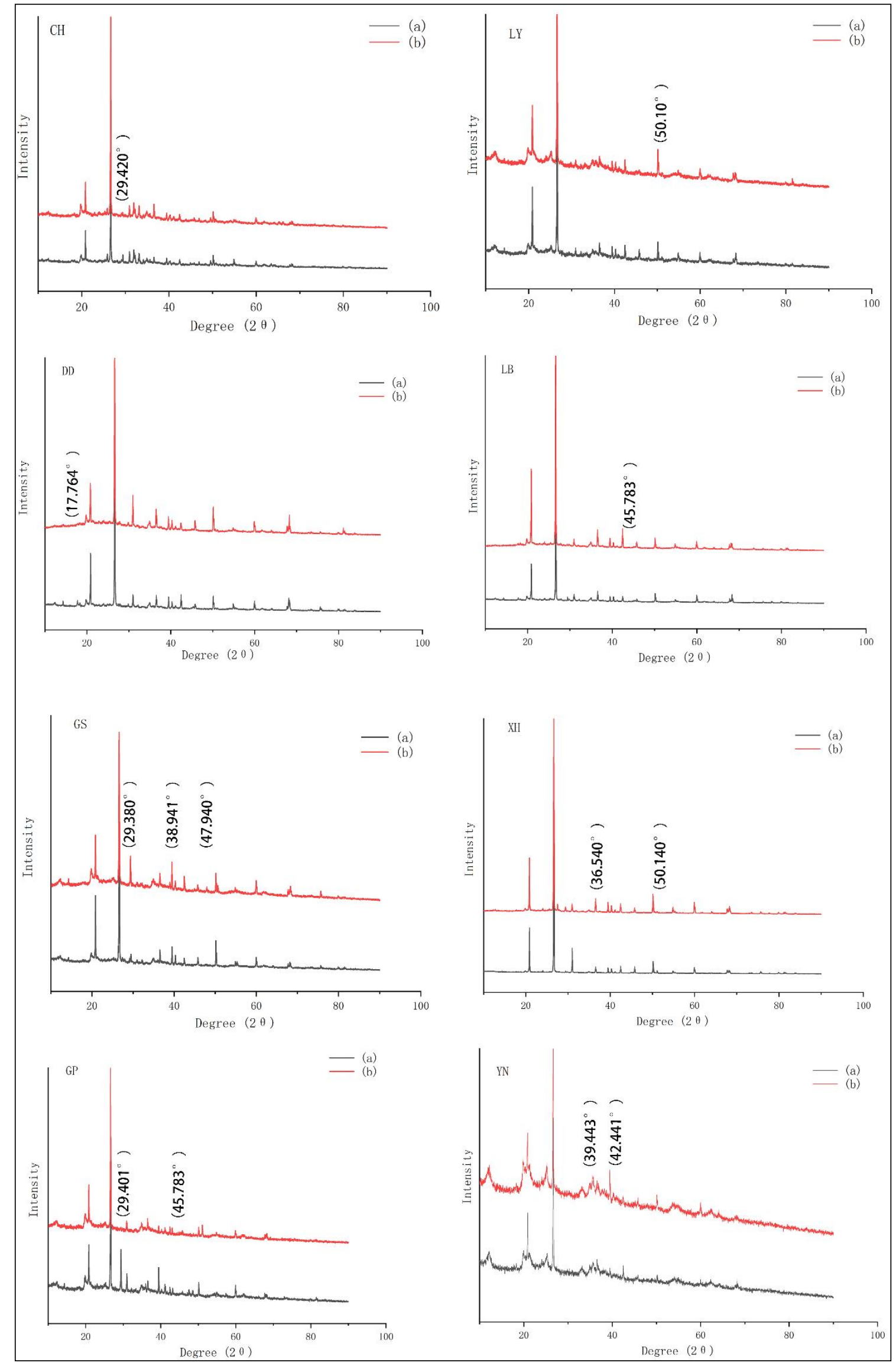


Figure 4. XRD spectra of $\mathrm{Cu}(\mathrm{a})$ before and (b) after adsorption into the iron-oxide-clay mineral complex.

After A absorbed $\mathrm{Cu}$, the characteristic peak of GS calcite $\left(29.380^{\circ}\right)$ was enhanced, and the characteristic peaks of platy alumina $\left(\mathrm{AlPO}_{4}\right)\left(38.941^{\circ}\right)$ and the iron compound $\mathrm{Fe}_{3}\left(\mathrm{PO}_{4}\right) 2 \cdot \mathrm{H}_{2} \mathrm{O}\left(47.940^{\circ}\right)$ appeared. $\mathrm{LY}$ quartz and platy alumina $\left(\mathrm{AlPO}_{4}\right)$ participated in the adsorption. After DD adsorbed $\mathrm{Cu}$, illite $\left(17.764^{\circ}\right)$ disappeared. The diffraction-peak intensity of quartz, dolomite, and zinc-calcium dolomite in $\mathrm{XH}$ increased significantly. In GP, the diffraction peak $\left(29.401^{\circ}\right)$ of calcite disappeared, and the diffraction peak $\left(51.080^{\circ}\right)$ of oxynitride $\left(\mathrm{Si}_{2} \mathrm{~N}_{2} \mathrm{O}\right)$ appeared. The diffraction peak $\left(45.783^{\circ}\right)$ of the LB medium plate bauxite $\left(\mathrm{AlPO}_{4}\right)$ was also enhanced, while the diffraction peak $\left(29.420^{\circ}\right)$ of quartz in $\mathrm{CH}$ disappeared. The characteristic peak $\left(39.443^{\circ}\right)$ of quartz in $\mathrm{YN}$ was enhanced, while the diffraction peak $\left(42.441^{\circ}\right)$ of kyanite $\left(\mathrm{Al}_{2} \mathrm{SiO}_{5}\right)$ was also weakened.

Thus, A was mainly adsorbed by calcite, the iron compound $\mathrm{Fe}_{3}\left(\mathrm{PO}_{4}\right)_{2} \cdot \mathrm{H}_{2} \mathrm{O}$, illite, quartz, dolomite, and $\mathrm{Cu}$. A previous study showed ${ }^{[19]}$ that calcite shows good adsorption of $\mathrm{PO}_{4}{ }^{3-}$, but there are relatively few studies on its adsorption of heavy metals. Illite, as a whole, is negatively charged and can adsorb positively charged $\mathrm{Cu}$. The adsorption method in this process is selective adsorption. Although quartz is the main component of sediments, it has a limited adsorption capacity, due to its small surface area, and is therefore rarely used in remediation of heavy metal pollution. However, in this study, we observed an enhancement in the diffraction peak of quartz, possibly due to $\mathrm{Cu}$ being covered by adsorption. The quartz on the surface of the deposit, moreover, caused disappearance of the diffraction peak ${ }^{[20]}$. The dolomites mainly entered the interlayer with heavy metals and underwent exchange with $\mathrm{Ca}, \mathrm{Mg}$, etc., resulting in heavy metal adsorption [21].

\subsubsection{Comparison of Group B before and after $\mathrm{Cu}$ Adsorption}

There were significant changes in the FTIR spectrum of the organic-clay mineral complex after $\mathrm{Cu}$ ion interaction (Figures 5). The stretching vibration peaks of $-\mathrm{OH}$ (3697.38-3394.57, 2309.69-2927.81, and 1417.61-1384.83 $\mathrm{cm}^{-1}$ ) moved and disappeared, indicating that $-\mathrm{OH}$ was involved in adsorption or complexation. The absorption peak of the carboxyl group ranged from 1435.05 to $1429.19 \mathrm{~cm}^{-1}$, indicating that after the carboxyl group came into contact with $\mathrm{Cu}$, a chemical bond of $-\mathrm{COO}$-metal was formed. The blue shift of 1006.79-1008.72 $\mathrm{cm}^{-1}$, corresponding to the Si-O-Si symmetrical stretching peak, indicates the occurrence of complexation or coordination. The $-\mathrm{CH}$ stretching vibration peaks of 2927.81-2925.88 and 1427.32-1382.96 $\mathrm{cm}^{-1}$ show that alkanes experienced a red shift, indicating that $\mathrm{Cu}$ complexed with $-\mathrm{CH}$ to form a metal complex. Moreover, red and blue shifts occurred at 1386.75-1029.94 and 428.17-472.31 $\mathrm{cm}^{-1}$, corresponding to the Si$\mathrm{O}-\mathrm{Si}$ symmetrical/bending stretching peaks, indicating that $\mathrm{Cu}$ entered the mineral interior and complexed. Blue shifting of the bending vibration peak of $\mathrm{Si}-\mathrm{O}$ occurred at $1641.35-1639.42,1433.04-1384.83$, and $432.47-433.78 \mathrm{~cm}^{-1}$, indicating the occurrence of hydrogen bonding with the complex. The symmetric stretching vibration peak of $\mathrm{Si}-\mathrm{O}$ at $603.69-599.83 \mathrm{~cm}^{-1}$ represents a red shift, indicating that charge transfer or surface complexation occurred. 

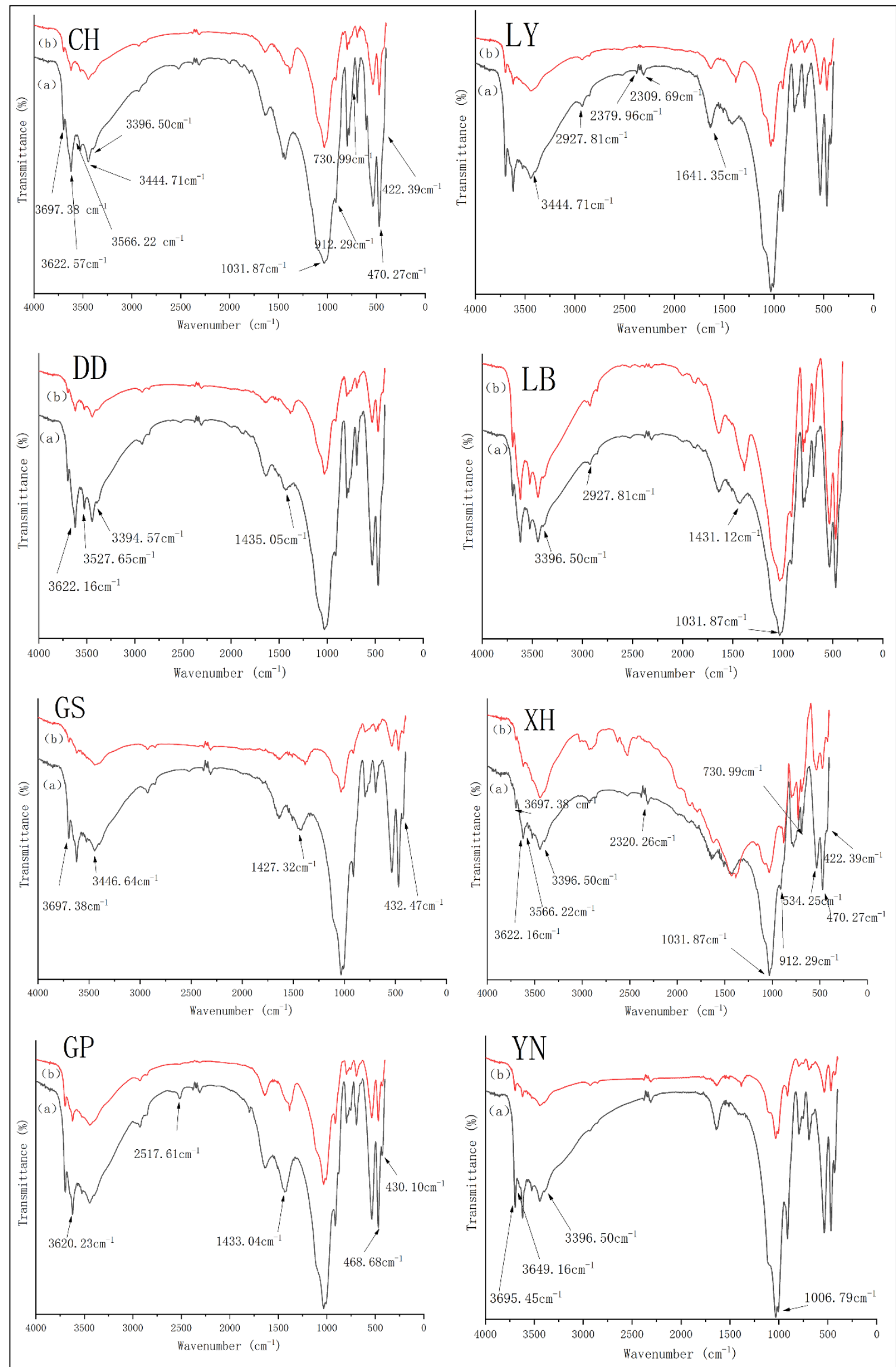

Figure 5. FTIR spectra of $\mathrm{Cu}$ (a) before and (b) after being adsorbed into the organic-clay mineral complex. 
In summary, the adsorption of $\mathrm{Cu}$ in Group $\mathrm{B}$ mainly occurred through functional groups such as $-\mathrm{OH}$, carboxyl, $-\mathrm{CH}$, silicide $(\mathrm{Si}-\mathrm{O}-\mathrm{Si}, \mathrm{Si}-\mathrm{O})$, etc., whose spectral characteristics indicating changes in hydrogen bonding through $\mathrm{Cu}$ adsorption, coordination, or complexation. 

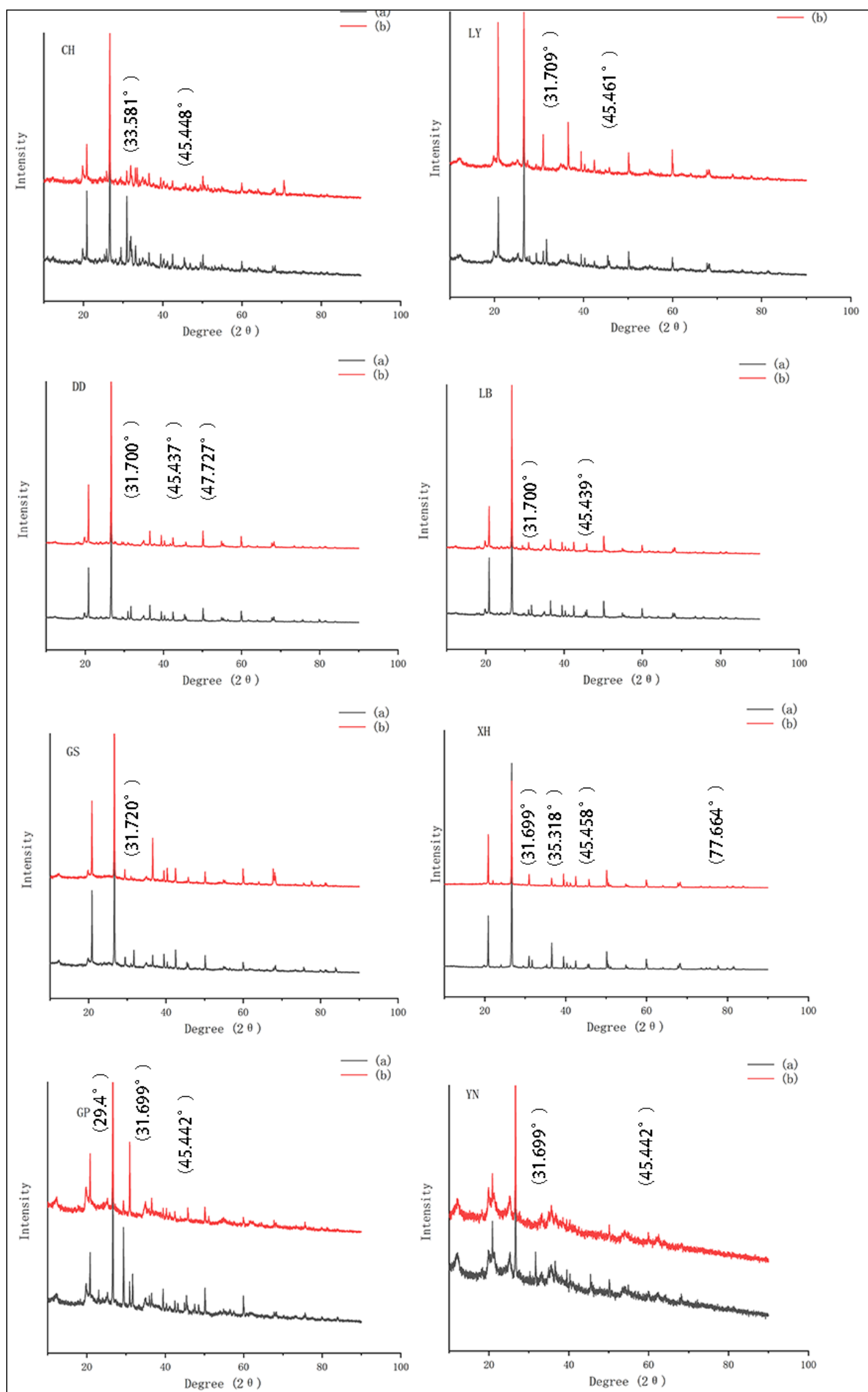

Figure 6. XRD spectra of $\mathrm{Cu}(\mathrm{a})$ before and (b) after being adsorbed into the organic-clay mineral complex. 
After the adsorption of $\mathrm{Cu}$ by B, the diffraction peaks of $31.700^{\circ}$ and $45.439^{\circ}$ for the salt rock in LB disappeared. In $\mathrm{XH}$, the diffraction peaks of graphite $\left(31.699^{\circ}\right.$ and $\left.35.318^{\circ}\right)$ and bauxite $\left(45.458^{\circ}\right.$ and $\left.77.664^{\circ}\right)$ disappeared. The diffraction peaks of calcite $\left(29.4^{\circ}\right)$ and kaolinite $\left(31.699^{\circ}\right.$ and $\left.45.442^{\circ}\right)$ in GP also disappeared. Moreover, the diffraction peak $\left(33.581^{\circ}\right)$ of the iron compound $\mathrm{Fe}_{3}\left(\mathrm{PO}_{4}\right)_{2} \cdot \mathrm{H}_{2} \mathrm{O}$ in $\mathrm{CH}$ appeared, and the diffraction peak $\left(45.448^{\circ}\right)$ of quartz disappeared. In $\mathrm{YN}$, the diffraction peaks $\left(31.699^{\circ}\right)$ of black stone and kaolinite $\left(45.442^{\circ}\right)$ disappeared. The diffraction peak $\left(31.720^{\circ}\right)$ of sepiolite $\left(\left(\mathrm{Si}_{12}\right)\left(\mathrm{Mg}_{8}\right)\right.$

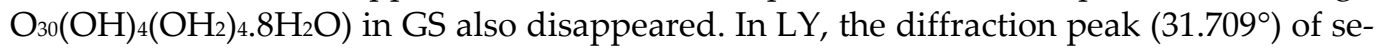
piolite $\left(\left(\mathrm{Si}_{12}\right)\left(\mathrm{Mg}_{8}\right) \mathrm{O}_{30}(\mathrm{OH})_{4}\left(\mathrm{OH}_{2}\right)_{4 .} 8 \mathrm{H}_{2} \mathrm{O}\right)$ and the characteristic peak $\left(45.461^{\circ}\right)$ of platy alumina disappeared. In DD, the diffraction peaks $\left(31.700^{\circ}\right.$ and $\left.45.437^{\circ}\right)$ of the salt rock disappeared, while the diffraction peaks $\left(47.727^{\circ}\right)$ of the iron compound $\mathrm{Fe}_{3}\left(\mathrm{PO}_{4}\right)_{2} \cdot \mathrm{H}_{2} \mathrm{O}$ appeared.

In summary, the adsorption of sepiolite in Group B occurred mainly through the compound $\mathrm{Fe}_{3}\left(\mathrm{PO}_{4}\right)_{2} \cdot \mathrm{H}_{2} \mathrm{O}$ of platy alumina and iron. There was a large amount of $\mathrm{Si}-\mathrm{OH}$ in sepiolite, which was able to complex with heavy metals on the surface. Heavy metal cations entered the sepiolite and underwent isomorphous displacement to achieve adsorption.

\subsubsection{Comparison before and after $\mathrm{Cu}$ adsorption in Group $\mathrm{C}$}

There were significant changes in the FTIR spectrum of the organic-inorganic complex after interacting with $\mathrm{Cu}$ ions (Figure 7). 

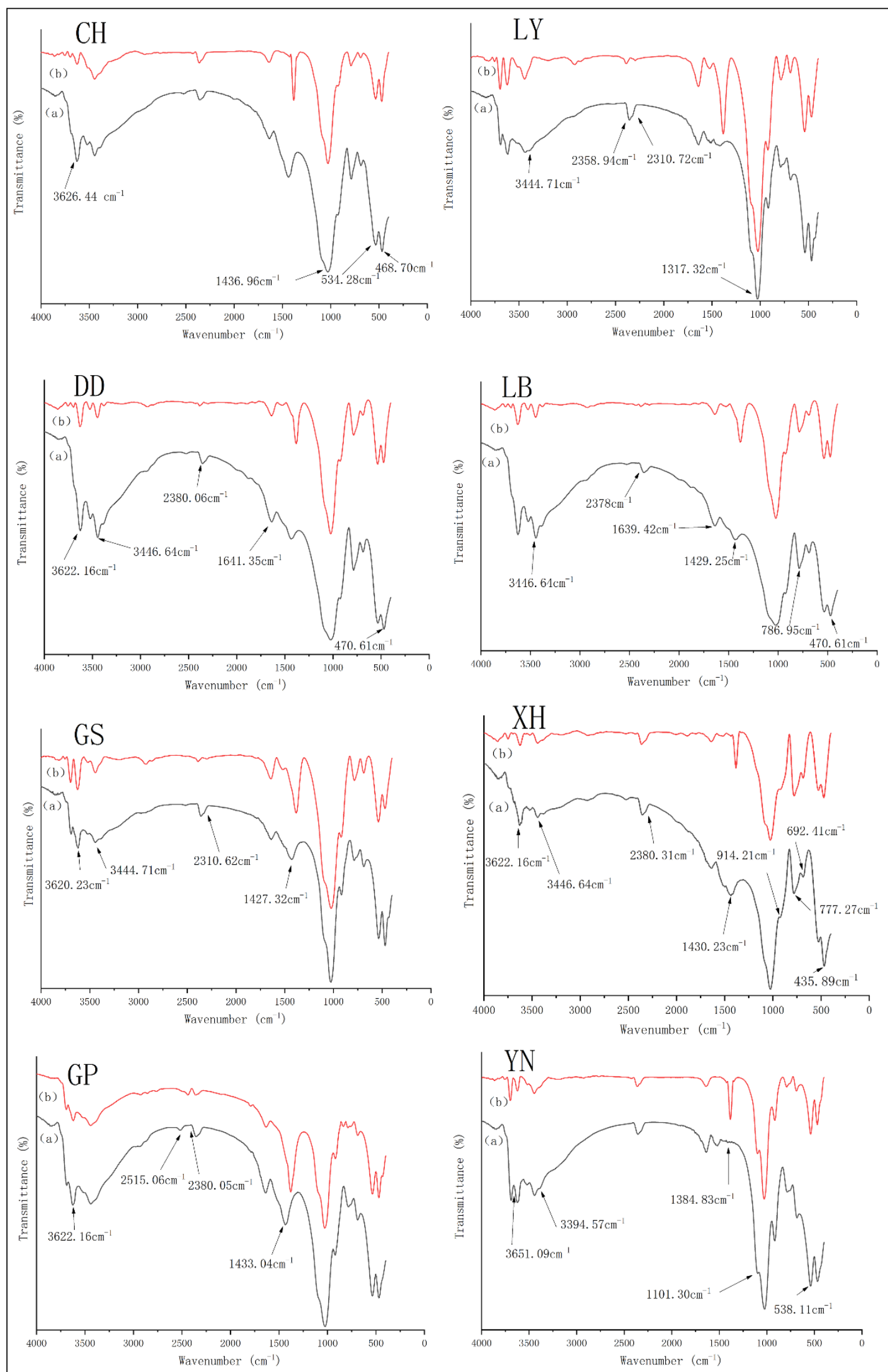

Figure 7. FTIR spectra of $\mathrm{Cu}$ before and after being adsorbed into the organic-inorganic complex: (a) before adsorption; (b) after adsorption. 
After the adsorption of $\mathrm{Cu}$, the absorption area where the peaks of group $\mathrm{C}$ moved, disappeared, or appeared was observed at 3697-3614 $\mathrm{cm}^{-1}$. This range corresponds to the -OH stretching vibration peaks of alcohols and phenols. After adsorption, this range moved, and the absorption peak disappeared, indicating that $\mathrm{Cu}$ and $-\mathrm{OH}$ complexed or coordinated. The -OH stretching vibration peak of the hydrogen bond in the alcohol molecule, the bending vibration peak of the carboxyl group and the absorption peak of interlayer water are red-shifted from $3446.64 \mathrm{~cm}^{-1}$ to $3394.57 \mathrm{~cm}^{-1}$, indicating that hydrogen bond formation has occurred. The absorption peaks of carbonates and ammonium salts (2355.92-2515.06 $\mathrm{cm}^{-1}$ ) disappeared, possibly due to their adsorption with carbonate minerals, and the Si-O-Si symmetrical stretching peak $\left(1022.27-1028.05 \mathrm{~cm}^{-1}\right)$ shifted, indicating that complexation or coordination occurred. The stretching vibration peak of $-\mathrm{CH}$ (918.11-921.97 $\mathrm{cm}^{-1}$ ) red- or blue-shifted, indicating that $\mathrm{Cu}$ complexed with -CH to form a metal complex. The red shift observed from 781.17 to $779.24 \mathrm{~cm}^{-1}$ indicates that quartz participated in the process of $\mathrm{Cu}$ adsorption. The Si-O-Si bending vibration peak (466.77$\left.474.48 \mathrm{~cm}^{-1}\right)$ and Si-O deformation vibration peak $\left(534.28-536.21 \mathrm{~cm}^{-1}\right)$ blue-shifted and disappeared, indicating that $\mathrm{Cu}$ entered the mineral interior and underwent complexation.

In general, functional groups such as alcohols, phenols, and carboxylic acids in Group $\mathrm{C}$ interacted with $\mathrm{Cu}$ to form inner complexes. Functional groups such as $-\mathrm{OH}, \mathrm{Si}-$ $\mathrm{O}-\mathrm{Si}$, and $-\mathrm{CH}$ participated in the $\mathrm{Cu}$ adsorption process through hydrogen bonding, complexation, and coordination. 


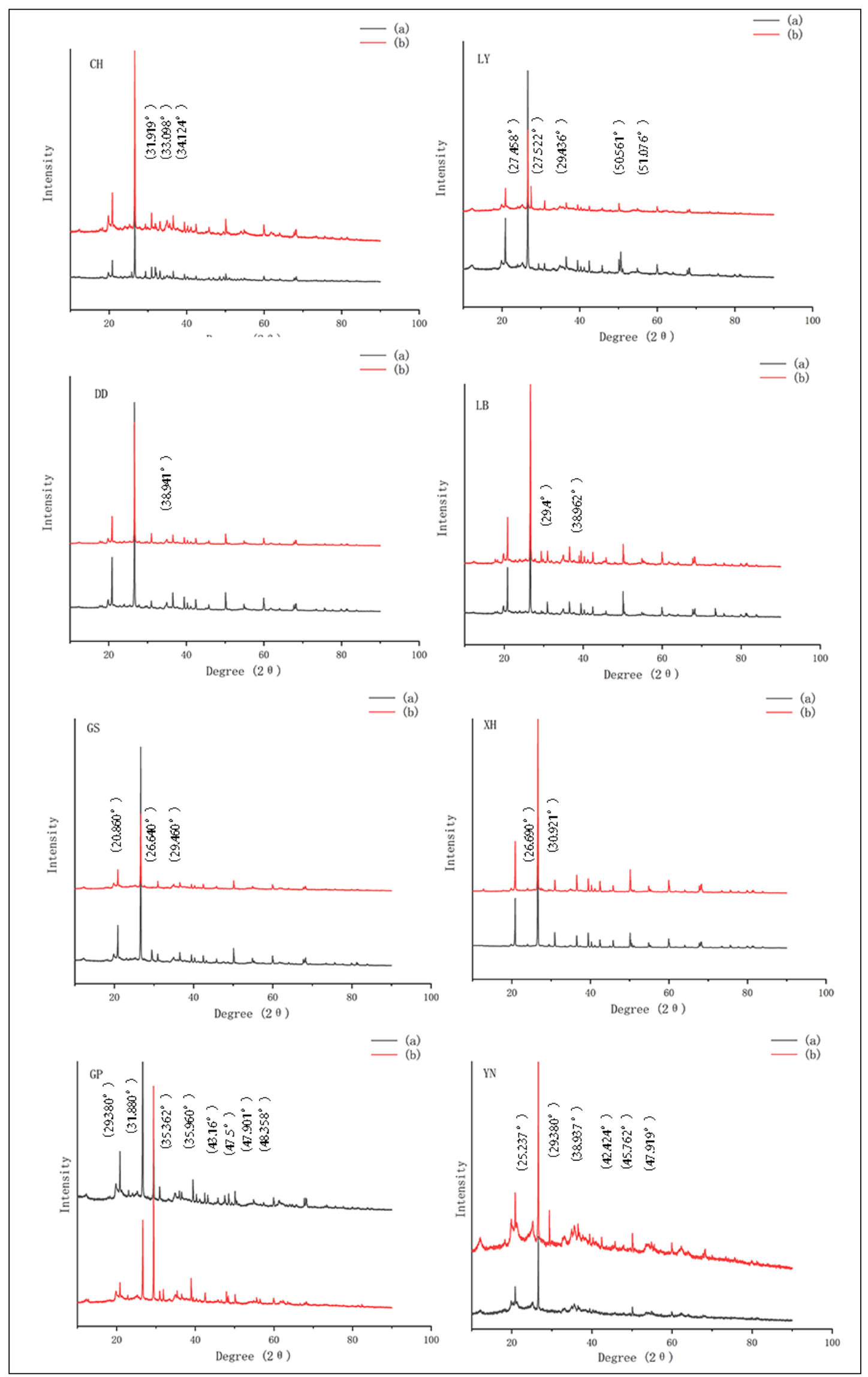

Figure 8. XRD spectra of $\mathrm{Cu}(\mathrm{a})$ before and (b) after being adsorbed into the organic-inorganic complex. 
In GS, the peak $\left(29.460^{\circ}\right)$ characteristic of calcite disappeared, and the characteristic peaks $\left(20.860^{\circ}\right.$ and $\left.26.640^{\circ}\right)$ of quartz $\left(\mathrm{SiO}_{2}\right)$ weakened. Moreover, the characteristic peaks $\left(27.458^{\circ}\right.$ and $\left.27.522^{\circ}\right)$ of illite appeared in LY, while the characteristic peaks $\left(29.436^{\circ}\right.$, $50.561^{\circ}$, and $\left.51.076^{\circ}\right)$ of the iron compound $\mathrm{Fe}_{3}\left(\mathrm{PO}_{4}\right) 2 \cdot \mathrm{H}_{2} \mathrm{O}$ disappeared. In DD, the quartz and agglomerate $\left(\mathrm{AlPO}_{4}\right)$ diffraction peaks were obviously weakened, indicating their participation in the adsorption process. The diffraction peaks in LB were not significantly weakened, though there was weakening of the characteristic peak of calcite $\left(29.4^{\circ}\right)$. Moreover, the peak of characteristic yellow molybdenum $\left(38.962^{\circ}\right)$ appeared. In $\mathrm{XH}$, the characteristic peaks of quartz $\left(26.690^{\circ}\right)$ and dolomite $\left(30.921^{\circ}\right)$ were weakened. In GP, the characteristic peaks of calcite $\left(29.380^{\circ}, 43.16^{\circ}\right.$, and $\left.47.5^{\circ}\right)$ and magnesium $\left(35.960^{\circ}\right)$ disappeared, while the characteristic peaks of the iron compound $\mathrm{Fe}_{3}\left(\mathrm{PO}_{4}\right)_{2} \cdot \mathrm{H}_{2} \mathrm{O}\left(31.880^{\circ}\right)$, magnetite $\left(35.362^{\circ}\right)$, and barium dolomite $\left(47.901^{\circ}\right.$ and $\left.48.358^{\circ}\right)$ appeared. Further, the characteristic peaks of muscovite $\left(31.919^{\circ}\right)$, mica $\left(33.098^{\circ}\right)$, and phlogopite $\left(34.124^{\circ}\right)$ in $\mathrm{CH}$ disappeared. In $\mathrm{YN}$, the characteristic peaks of kaolinite $\left(25.237^{\circ}\right)$, calcite $\left(29.380^{\circ}\right)$, quartz $\left(38.937^{\circ}\right.$ and $\left.42.424^{\circ}\right)$, and the iron compound $\left(\mathrm{Fe}_{3}\left(\mathrm{PO}_{4}\right) 2 \cdot \mathrm{H}_{2} \mathrm{O}\right)\left(45.762^{\circ}\right.$ and $\left.47.919^{\circ}\right)$ appeared.

During the adsorption of $\mathrm{Cu}$ in Group $\mathrm{C}$, we found that the diffraction peaks of calcite, the iron compound $\mathrm{Fe}_{3}\left(\mathrm{PO}_{4}\right)_{2} \cdot \mathrm{H}_{2} \mathrm{O}$, and mica species disappeared after $\mathrm{Cu}$ adsorption, indicating that these materials participated in the adsorption process and that $\mathrm{Cu}$ entered the interlayer, changing the crystal structure. The diffraction peaks of illite, yellow molybdenite, magnetite, and kaolinite appeared, indicating that $\mathrm{Cu}$ was adsorbed on the surface.

\section{Discussion and Analysis}

4.1. Mechanism of $\mathrm{Cu}$ Adsorption by the Sediment Complex 

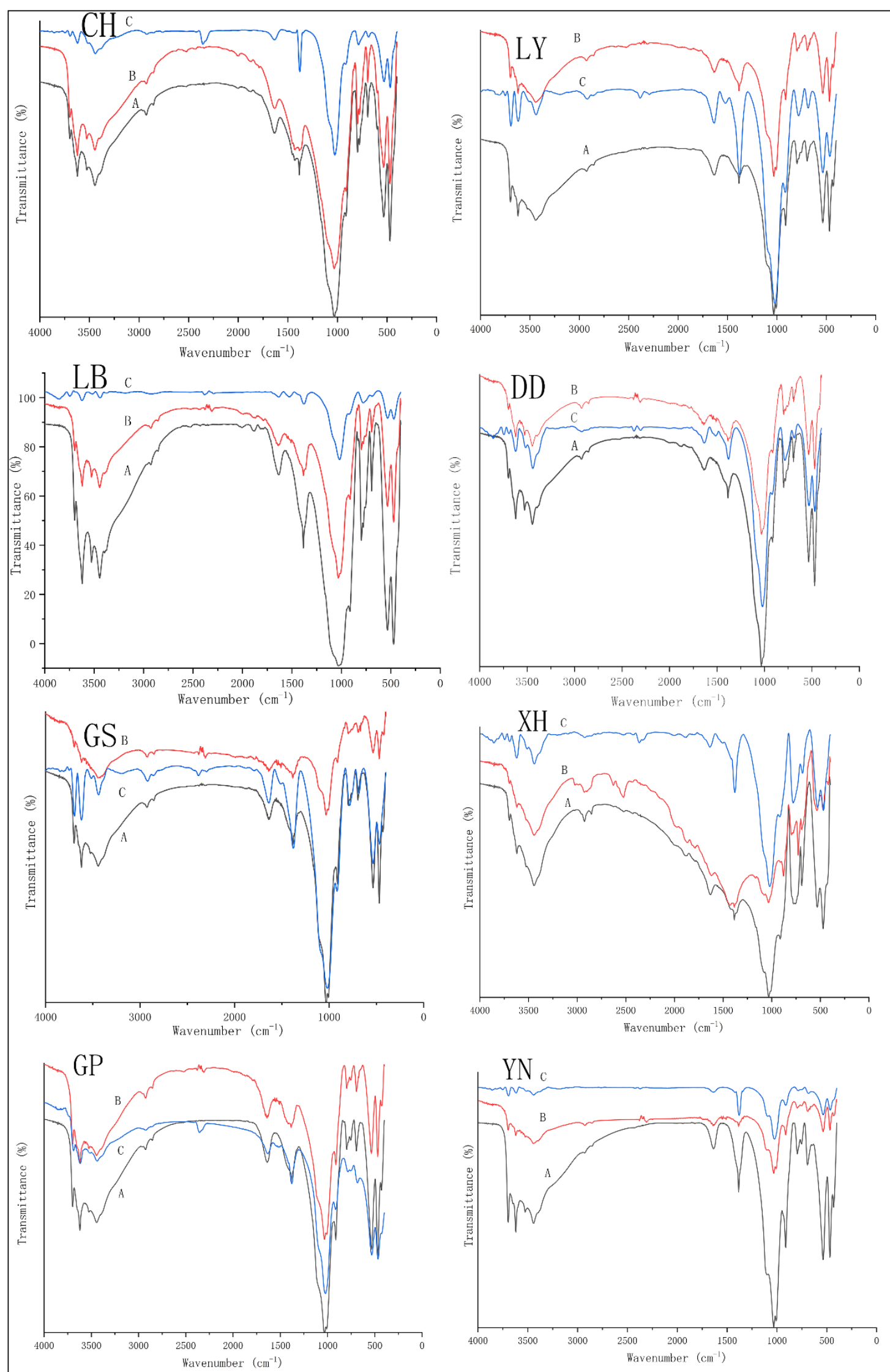

Figure 9. Fourier transform infrared spectra of copper ions adsorbed by three complexes in the sediments: Group A is the ironoxide-clay mineral complex; Group B is an organic-clay mineral complex; Group C is an organic-inorganic mineral complex. 
Table 3. Table of semi-quantitative parameters of Fourier infrared spectroscopy.

\begin{tabular}{|c|c|c|c|c|c|c|}
\hline \multirow{2}{*}{$\begin{array}{l}\text { Wave number } \\
\qquad\left(\mathrm{m}^{-1}\right)\end{array}$} & \multicolumn{3}{|c|}{ Before adsorption } & \multicolumn{3}{|c|}{ After adsorption } \\
\hline & $\mathrm{A}$ & $\mathrm{B}$ & $\mathrm{C}$ & A & B & $\mathrm{C}$ \\
\hline 796 & $2.10 \pm 1.80$ & $2.27 \pm 1.57$ & $1.78 \pm 2.09$ & $0.78 \pm 0.47$ & $0.86 \pm 0.39$ & $1.20 \pm 0.89$ \\
\hline 3446 & $26.23 \pm 5.14$ & $25.83 \pm 4.03$ & $53.15 \pm 6.39$ & $12.71 \pm 8.17$ & $11.46 \pm 7.63$ & $5.04 \pm 2.91$ \\
\hline 3622 & $4.98 \pm 0.98$ & $4.84 \pm 0.97$ & $4.07 \pm 0.57$ & $4.35 \pm 1.28$ & $3.45 \pm 1.53$ & $2.06 \pm 0.52$ \\
\hline 3697 & $2.53 \pm 0.70$ & $2.67 \pm 0.51$ & $2.64 \pm 0.70$ & $1.76 \pm 0.73$ & $1.95 \pm 0.87$ & $1.08 \pm 0.70$ \\
\hline
\end{tabular}
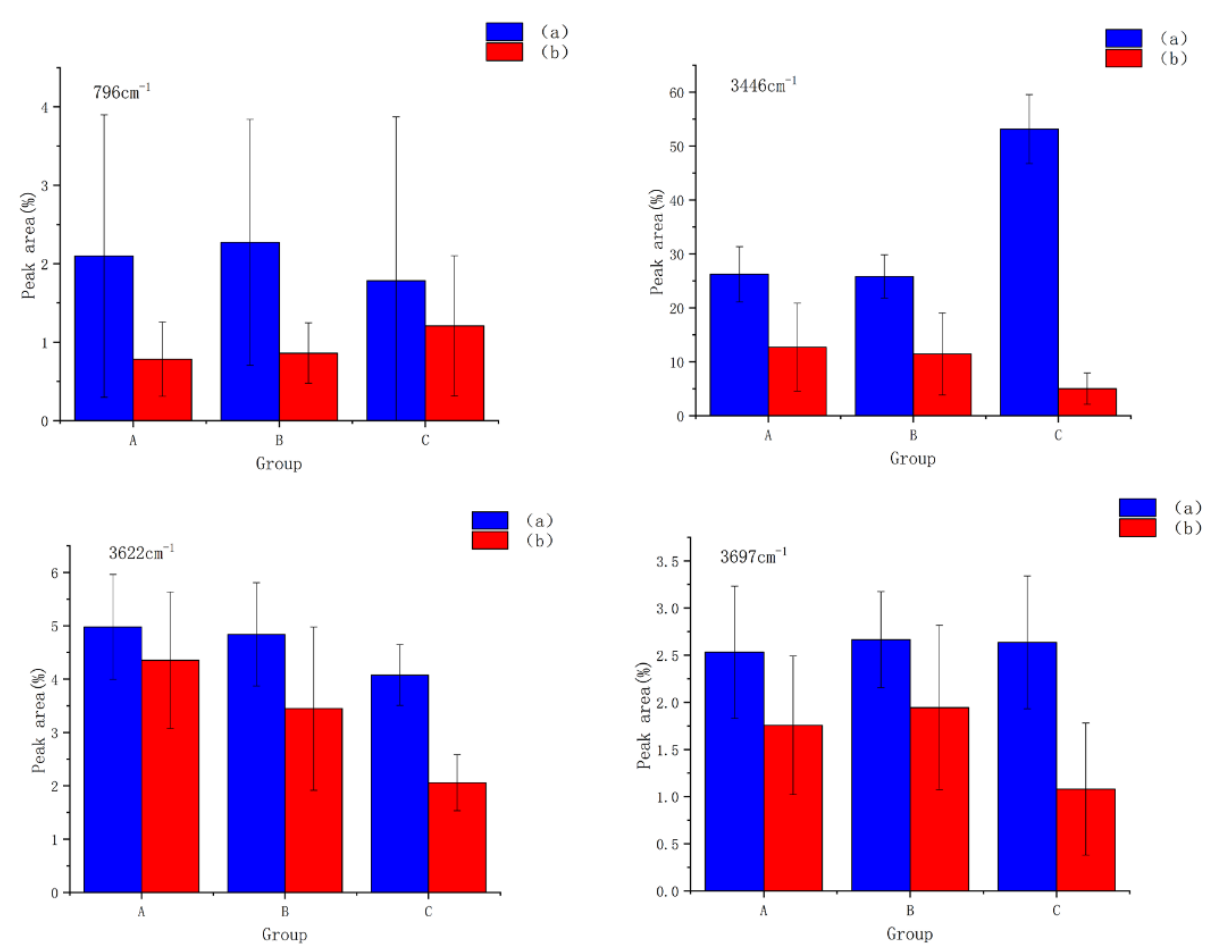

Figure 10. Mechanism of $\mathrm{Cu}$ Adsorption by the Sediment Complex. (a) Before adsorption; (b) after adsorption

According to Table 3 and Figure 10, there are significant differences in the peak areas of these functional groups before and after adsorption. When the $\mathrm{C}$ group adsorbed $\mathrm{Cu}$, the spectral characteristics in the mid-infrared region $\left(4000-400 \mathrm{~cm}^{-1}\right)$ showed that most of the - $\mathrm{OH}$ from alcohol, phenol and carboxylic acid participated in the $\mathrm{Cu}$ adsorption process through the direct complexation of these functional groups. It can also be seen from Table 3 that the group $\mathrm{C}$ peaks $\left(>3000\left(\mathrm{~cm}^{-1}\right)\right)$ belong to the stretching vibration peaks of the $-\mathrm{OH}$ vibration peaks of alcohols, phenols and carboxylic acids. The peak area of group $\mathrm{C}$ in this region is smaller than that of group $\mathrm{B}$ and group $\mathrm{A}$, indicating that group $\mathrm{C}$ mainly undergoes coordination and complexation reaction with copper ions through functional groups such as carboxyl groups, resulting in the smallest peak area of group $C$. The peak areas of groups A, B, and C all showed a certain downward trend before and after adsorption. The peak area of each functional group in groups A and B showed a downward trend after absorbing copper ions, while the peak area of group $C$ decreased the most at $3446 \mathrm{~cm}-1$, which was much larger than the other two groups. It is speculated that the carboxyl groups of group $\mathrm{C}$ play a dominant role in the adsorption process in copper ions. The strength of the adsorption capacity among the three groups is: $C>B>A$. 
The biggest difference between group $\mathrm{C}$, group $\mathrm{A}$, and group $\mathrm{B}$ is the difference in organic matter content. The order of organic matter content is: $C>B>A$. Generally, in the presence of a high concentration of organic matter, the organic matter will be combined with the surface of the mineral, making it difficult for copper ions to approach the surface of the mineral, resulting in the adsorption of copper ions to the surface of the mineral without the intervention of water molecules, which is formed by replacing surface protons $(\mathrm{H}+)$ Specific adsorption (inner ring complex) or metal cations combine with functional groups in the organic matter that are not bound to the mineral surface sites to form a type B ternary complex. In the presence of a low concentration of organic matter, copper ions will form an inner ring complex with the surface of the clay mineral, and then coordinate with the carboxyl or phenolic group of the organic matter to form a cationic bridged A-type ternary complex. It can be seen that the $\mathrm{C}$ and $\mathrm{B}$ groups belong to the characteristics of the B-type ternary complex. Organic matter has a great influence on the adsorption capacity. Therefore, it is speculated that the reason may be related to the carboxyl, carbonyl and phenol functional groups on the surface of the organic matter. This also echoes the situation where the peak area $\left(3446 \mathrm{~cm}^{-1}\right)$ changes the most. The A group is dominated by iron oxide, which is a low concentration of organic matter concentration, and is mainly dominated by type A ternary complexes. These functional groups and metal oxides formed an organic film, which improved surface activity and enhanced the adsorption capacity of clay minerals ${ }^{[22]}$. Silicides (e.g., Si-O-Si and Si-O-Mg stretching vibrations) and -CH participated in the specific adsorption of $\mathrm{Cu}$ through hydrogen bonding, complexation, and coordination. The $\mathrm{K}_{\mathrm{f}}$ value of Group $\mathrm{C}$ was the largest, so the adsorption capacity of $\mathrm{Cu}$ in Group C was stronger than that in Groups A and B.

Furthermore, the separation factor of Group $C$ approached 0 because functional groups such as alcohols, phenols, and carboxylic acids provided multiple adsorption sites. Then, $\mathrm{Cu}$ combined with functional groups through chemical bonds to achieve chemical adsorption. This chemical adsorption featured a strong binding force, making desorption very difficult (i.e., the adsorption was irreversible).

The changes in the wave number range of $1000-400 \mathrm{~cm}^{-1}$ in Group A indicate that after organic matter was removed, an organic film formed on the surface and the quantity of clay minerals was reduced, which reduced the activity of clay mineral silicides as well as the ability of silicides to participate in adsorption. The polar functional groups of alcohols, such as phenol and carboxyl groups, participated not only in adsorption through hydrogen bonding and ion exchange but also in the adsorption of $\mathrm{Cu}$ through coordination exchange, which increased the adsorption capacity $\mathrm{K}_{\mathrm{f}}$ of the adsorbent and also increased the isotherm adsorption curve with a degree of nonlinearity.

In the wavenumber range of $4000-3000 \mathrm{~cm}^{-1}$, the number of functional groups significantly involved in the adsorption of alcohols and phenols in Group B was greater than that in Group A. The corresponding peak area of group A is also larger than that of group B. Therefore, the reduction in polar functional groups such as alcohols, phenols, and carboxyl groups in Group A not only reduced their comparative involvement in adsorption in Group A but also the activity of silicon compounds, thus increasing the separation factor of Group A (tending toward 1). The $\mathrm{K}_{\mathrm{f}}$ value of Group B was larger, and the separation factor showed a favorable adsorption process.

Therefore, based on the results of Fourier infrared spectroscopy, the number of functional groups involved in the adsorption of Group C was the largest, followed by that in Group A and then Group B. In terms of the types of functional groups involved in adsorption, Group $\mathrm{C}$ was dominated by polar functional groups (alcohols, phenols, and carboxylic acids), silicides ( $\mathrm{Si}-\mathrm{O}-\mathrm{Si}$ and $\mathrm{Si}-\mathrm{O}-\mathrm{Mg}$ ), and $-\mathrm{CH}$ functional groups and provided sites for irreversible adsorption. The removal of organic matter in Group A reduced the presence of polar functional groups such as alcohols, phenols, and carboxyl groups; decreased the activity of silicides; and also reduced the ability to participate in adsorption. Group B featured more functional groups involved in adsorption and had a stronger adsorption capacity. Moreover, after the organic matter of Group A was removed, not only did the functional groups that participated in adsorption through coordination exchange 
decrease but the activity of silicides was also reduced, thereby determining the order for the adsorption of heavy metals as the following: Group C > Group B > Group A. This result is consistent with the results of the adsorption capacity analysis.

Table 4. Correlation analysis between reaction conditions and model coefficients.

\begin{tabular}{|c|c|c|c|c|c|c|c|}
\hline & Free Iron Oxide & $\mathrm{pH}$ & DOM & CEC & $\mathrm{K}_{\mathrm{f}}$ & $1 / \mathrm{n}$ & $\mathrm{R}^{2}$ \\
\hline Free Iron Oxide & 1 & & & & & & \\
\hline $\mathrm{pH}$ & & 1 & & & & & \\
\hline DOM & & & 1 & & & & \\
\hline CEC & & & $.704^{* *}$ & 1 & & & \\
\hline $\mathrm{K}_{\mathrm{f}}$ & & & $.498^{*}$ & $.538^{* *}$ & 1 & & \\
\hline $1 / \mathrm{n}$ & & & & & $-.474^{*}$ & 1 & \\
\hline $\mathrm{R}^{2}$ & & & & & & & 1 \\
\hline
\end{tabular}

According to Table 4, in addition to organic matter, there is another important factor that affects the size of $\mathrm{K}_{\mathrm{f}}$, that is, CEC. The CEC content determined by the surface properties of the sediment colloid is mainly related to the negatively charged clay mineral sites and the content of dissociated SOM carboxyl groups ${ }^{[23]}$. As can be seen from Table 4, CEC is positively correlated with DOM. With the increase of DOM, CEC increases and Kf increases. SOM can not only directly promote the adsorption of copper ions by forming ternary surface complexes and directly complexing heavy metal copper with functional groups, but also promote the adsorption of copper ions by affecting CEC content. Thus, $\mathrm{SOM}$ is in the process of daughter-in-law.

\subsection{Effects of Clay Mineral Composition and Structure on Cu Adsorption via Sediment Com- plexes}

As shown in Figure 12, after the sediment complex adsorbed $\mathrm{Cu}$, the number of diffraction peaks appearing or disappearing in the XRD spectrum appeared in the following order: Group C > Group B > Group A. The diffraction peaks that changed in Group C were mainly those of illite, quartz, kaolinite, calcite, yellow molybdenum, iron compound $\mathrm{Fe}_{3}\left(\mathrm{PO}_{4}\right)_{2} \cdot \mathrm{H}_{2} \mathrm{O}$, agglomerate, dolomite, and mica. The diffraction peaks that changed in Group A mainly included those of calcite, iron compound $\mathrm{Fe}_{3}\left(\mathrm{PO}_{4}\right)_{2} \cdot \mathrm{H}_{2} \mathrm{O}$, illite, quartz, dolomite, and silicon oxynitride $\left(\mathrm{Si}_{2} \mathrm{~N}_{2} \mathrm{O}\right)$. The diffraction peaks that changed in Group $B$ mainly included those of salt rock, calcite, kaolinite, quartz, platylite, iron compound $\mathrm{Fe}_{3}\left(\mathrm{PO}_{4}\right)_{2} \cdot \mathrm{H}_{2} \mathrm{O}$, and sepiolite. It can be seen that the minerals involved in adsorption were also present in the following order: Group C > Group B > Group A. Here, the number of adsorbed minerals in Group B was not very different from that in Group A, but the specific surface area and pore capacity of sepiolite in Group B were relatively large. A large amount of $\mathrm{Si}-\mathrm{OH}$ can be complexed with heavy metals on the surface, and heavy metal cations can enter the sepiolite to undergo isomorphous replacement, thereby achieving adsorption. Therefore, the adsorption capacity of Group B was stronger than that of Group A. In this way, the adsorption capacity of sediments in each group can be ordered as follows: Group C > Group B > Group A. 

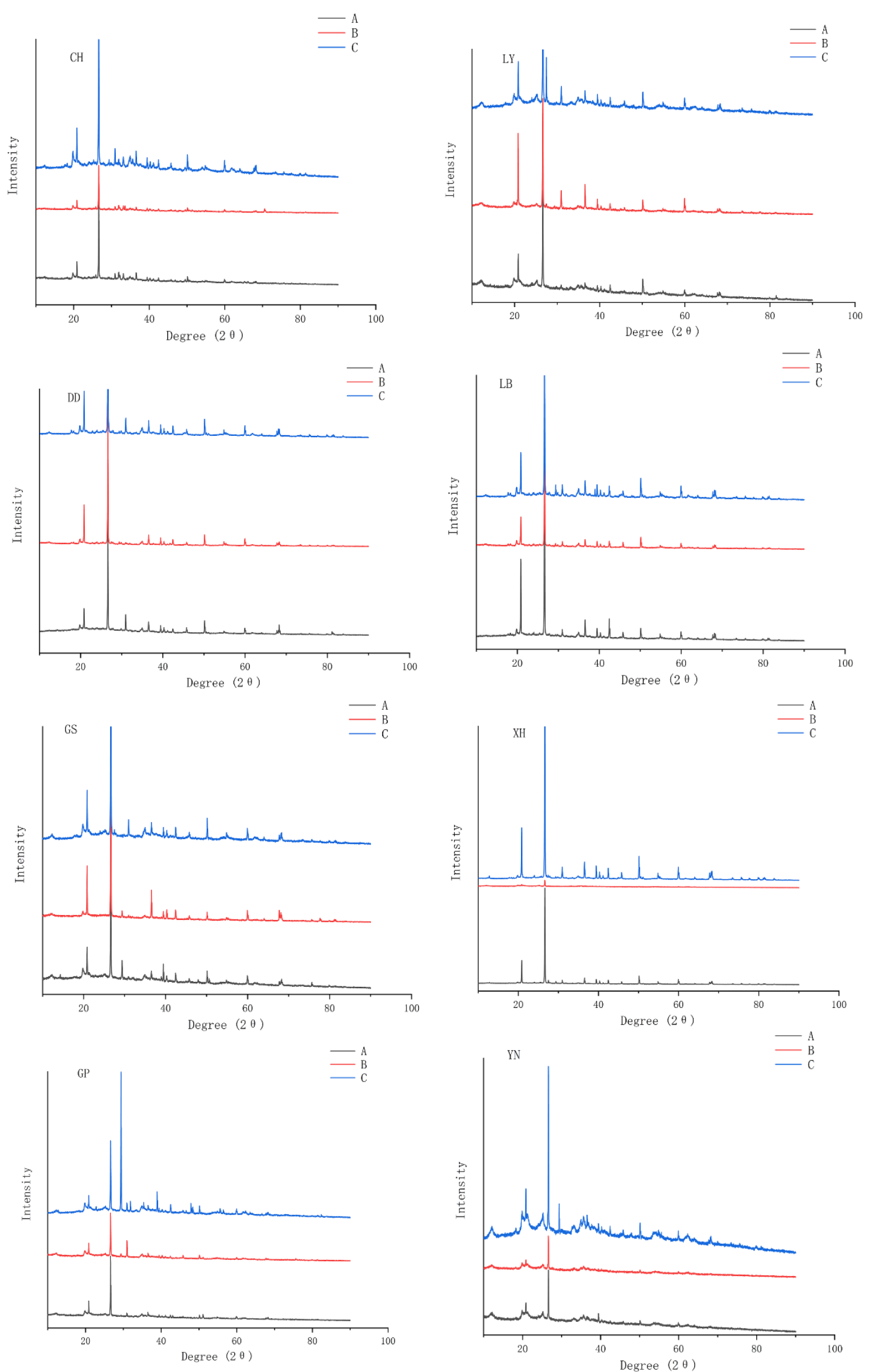

Figure 12. XRD patterns of copper ions adsorbed by the three complexes in the sediments. Group A is the iron-oxide-clay mineral complex; Group B is the organic-clay mineral complex; Group C is the organic-inorganic complex. 
In summary, the number of adsorbed minerals in Group $C$ along with the sepiolite in Group B made the adsorption capacity of $\mathrm{Cu}$ in these two groups stronger than that in Group A.

Scanning electron microscopy was performed to further analyze the structural differences in the samples obtained after the three types of complexes adsorbed $\mathrm{Cu}$, and the results are shown in Figure 11. As can be seen in Figure 11, there were few differences in the SEM images of the samples from different rivers in Groups A, B, and C after Cu adsorption. For further observations, we randomly selected SEM images of $\mathrm{Cu}$ adsorption by the three groups of complexes in the river of GS.

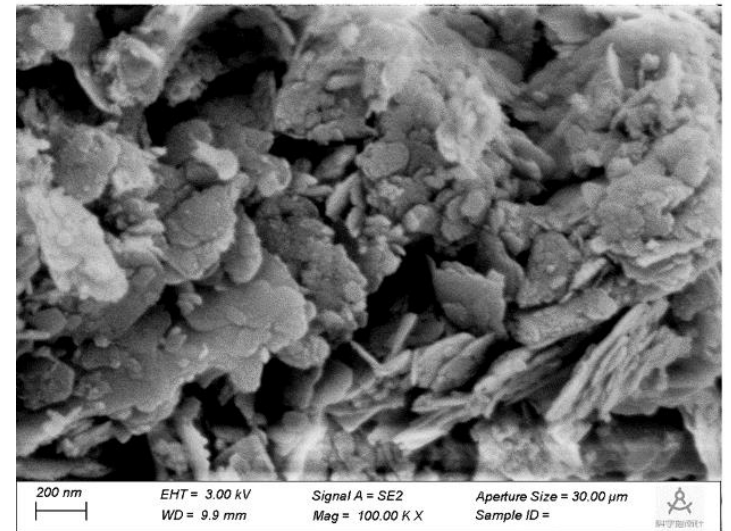

(a)

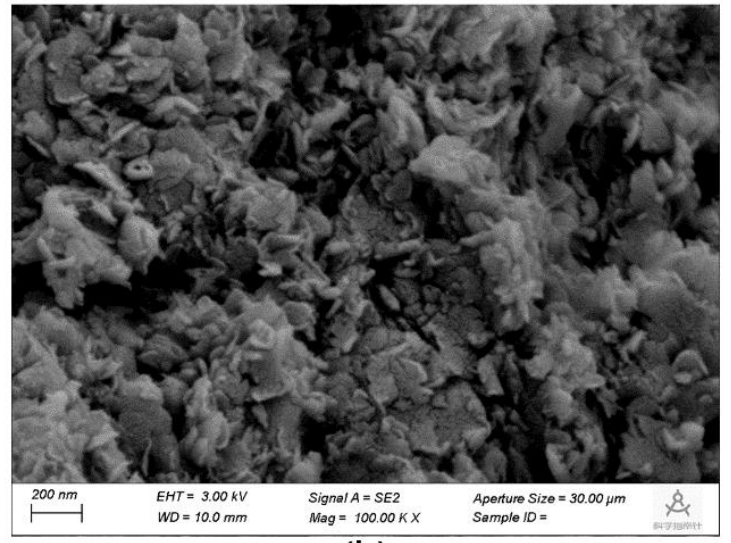

(b)

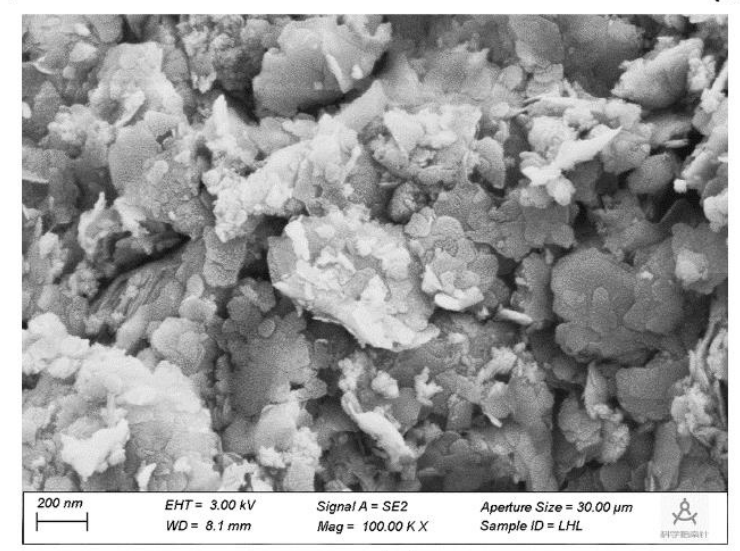

(c)

Figure 13. Scanning electron microscopy (SEM) results for the three kinds of $\mathrm{Cu}$ adsorption complexes in GS: (a) ironoxide-clay mineral complex; (b) organic-matter-clay mineral complex; (c) organic-inorganic complex.

The three sets of sediment complexes all showed significant lamellar structures with rough surfaces with clay platelets both stacked on and perpendicular to each other and compact arrangements. Among them, the lamellar structure of Group B was the most dense and the presence of organic matter increases the surface roughness. Such surface features help expose the functional groups and provide a large number of adsorption sites. Group C was second most dense, and Group A was the least dense. However, the specific surface area of group $C$ is much larger than that of group $B$. The microstructure of group $C$ contains both organic matter (represented by carbon atoms) and iron oxide (represented by iron atoms), which promotes the adsorption of copper ions. Therefore, the results correspond to the following order of adsorption capacity: Group B > Group C $>$ Group A. 


\section{Conclusions}

The Langmuir isotherm adsorption equation showed that the adsorption of $\mathrm{Cu}$ by the composite occurred through monolayer adsorption, while the Freundlich adsorption isotherm equation indicated that the adsorption of $\mathrm{Cu}$ by the composite occurred through multi-molecular-layer adsorption. From highest to lowest, the adsorption capacity was in the order organic-inorganic complex > organic-matter-clay mineral complex $>$ iron-oxide-clay mineral complex.

FTIR analysis showed that the adsorption of $\mathrm{Cu}$ by the composite was mainly related to the $-\mathrm{OH}$ in the alcohols, phenols, and carboxylic acids contained in the composite-i.e., the application of coordination exchange, cation bridges, hydrogen bonds, and van der Waals forces involved in the binding of $\mathrm{Cu}$ to the clay mineral surface. Group $\mathrm{C}$ had the largest number of functional groups involved in adsorption, in which polar functional groups (alcohols, phenols, and carboxylic acids), silicides ( $\mathrm{Si}-\mathrm{O}-\mathrm{Si}$ and $\mathrm{Si}-\mathrm{O}-\mathrm{Mg}$ ), and $\mathrm{CH}$ functional groups dominated. In these functional groups, many irreversible adsorption sites were provided for adsorption, so the adsorption capacity of organic-inorganic composites for $\mathrm{Cu}$ was observed to be stronger than that for the other two groups. The removal of organic matter in Group A reduced the presence of polar functional groups, including alcohols, phenols, and carboxyl groups, and reduced the activity of silicides, resulting in a decrease in the adsorption capacity, thus determining the order of $\mathrm{Cu}$ adsorption as $\mathrm{C}>\mathrm{B}>\mathrm{A}$. After each sediment complex adsorbed $\mathrm{Cu}$, the number of diffraction peaks that appeared or disappeared in the XRD spectrum was $C>B>A-$ that is, the adsorption capacity of each group of sediments was C $>$ B $>$ A. Analysis showed that sepiolite was the clay mineral that caused differences in the adsorption capacities of the two groups of sediment complexes. The number of minerals involved in the adsorption of Group C was significantly higher than that of the other two groups. The specific surface area and pore capacity of sepiolite in Group B were relatively large; thus, the adsorption capacity of Group B was stronger than that of Group A. In this way, the adsorption capacity of the sedimentary complexes in each group was as follows: Group C > Group B > Group A. This outcome is consistent with the results of the adsorption isotherm equation presented above. It is of great significance for the treatment of heavy metals in water and the immobilization of heavy metals in sediments. At the same time, it is concluded that wetland matrix remediation materials adsorbing heavy metals can also be formed.

Author Contributions: L.L: conceptualisation, supervision, formal analysis and editing. Y.-c.F.: data curation and visualization. X.-l.S.: review. All authors reviewed the manuscript.

Funding: This study was sponsored by the General Project of The National Natural Science Foundation of China (41463012).

Institutional Review Board Statement: Not applicable.

Informed Consent Statement: Not applicable.

Data Availability Statement: Data sharing not applicable.

Conflicts of Interest: The authors declare no conflict of interest.

\section{References}

[1] F P J, H S Y, P Y, et al. The remediation of heavy metals contaminated sediment[J]. Journal of Hazardous Materials, 2009, 161(2-3):633-640.

[2] S M X, L L, C F Y, et al. The adsorption characteristics of Cu(II) and $\mathrm{Zn}$ (II) on the sediments at the mouth of a typical urban polluted river in Dianchi Lake: taking Xinhe as an example[J]. Scientific Reports, 2021, 11(1):17067.

[3] S B, Y Y, C X, et al. Distribution of heavy metals and environmental assessment of surface sediment of typical estuaries in eastern China[J]. Marine Pollution Bulletin, 2017, 121(1-2):357-366.

[4] G F-M B, E P, K P. Carbohydrate biopolymers, lignin based adsorbents for removal of heavy metals $(\mathrm{Cd} 2+, \mathrm{Pb} 2+, \mathrm{Zn} 2+)$ from wastewater, regeneration and reuse for spent adsorbents including latent fingerprint detection: A review[J]. Biotechnology Reports, 2021, 30:e00609. 
[5] W B G, J G, U H. Heavy metal species, mobility and availability in soils[J]. Journal of Plant Nutrition and Soil Science = Zeitschrift fuer Pflanzenernaehrung und Bodenkunde, 2010, 149(4):382-398.

[6] A K, A M M, A Z, et al. Tamanrasset's Clay Characterization and Use as Low Cost, Ecofriendly and Sustainable Material for Water Treatment: Progress and Challenge in Copper Cu (II)[J]. Defect and Diffusion Forum, 2021, 406:457-472.

[7] J H, PéREZ-COVETA O. Soil salinity changes over 24 years in a Mediterranean irrigated district[J]. Geoderma, 2005, 125(3-4):287-308.

[8] X L, F L, Z W. Study on factors affecting determination of soil carbon by total organic carbon analyzer[J]. Analytical Instrumentation, 2011.

[9] R D, S K. Three New, Quick CEC Methods for Determining the Amounts of Exchangeable Calcium Cations in Calcareous Clays[J]. Clays \& Clay Minerals, 2009, 57(3):338-352.

[10] H S C, Y J P, H H H, et al. Arsenic sequestration in iron plaque and its effect on As uptake by rice plants grown in paddy soils with high contents of As, iron oxides, and organic matter[J]. Soil Science \& Plant Nutrition, 2013, 59(3):463-471.

[11] J S-Y, M E, M G, et al. Kinetics, adsorption and desorption of Cd(II) and Cu(II) on natural allophane: Effect of iron oxide coating[J]. Geoderma, 2018, 319:70-79.

[12] A B C, W K G. Pretreatment for mineralogical analysis[J]. Agronomy (USA), 1986.

[13] W L Z, B H, Q H J, et al. Influence of removal of organic matter and iron and manganese oxides on cadmium adsorption by red paddy soil aggregates[J]. RSC Advances, 2015, 5(110):90588-90595.

[14] P M O, L J M. Iron oxide removal from soils and clays by a dithionite citrate system buffered with sodium bicarbonate[J]. Clays and Clay Minerals, 1960, 7:313-317.

[15] S-Y, E M, G M, et al. Kinetics, adsorption and desorption of Cd(II) and $\mathrm{Cu}(\mathrm{II})$ on natural allophane: Effect of iron oxide coating[J]. Geoderma, 2018, 319:70-79.

[16] P E A, M B J. Dispetsion of soil particles by sonic Vibration[J]. Journal of Soil Science, 1967, 18.

[17] A M, E F O, G S S, et al. Sorption of $\mathrm{Zn}(\mathrm{II})$ and $\mathrm{Cu}(\mathrm{II})$ by four Argentinean soils as affected by pH, oxides, organic matter and clay content[J]. Environmental Earth Sciences, 2015, 74(5):4201-4214.

[18] A J A, Z M A A, A S, et al. Isotherm studies of lead(II), manganese(II), and cadmium(II) adsorption by Nigerian bentonite clay in single and multimetal solutions[J]. Particulate Science And Technology, 2018, (1):1-11.

[19] U B, D D, A E, et al. "Active filtration" for the elimination and recovery of phosphorus from waste water[J]. Colloids \& Surfaces A Physicochemical \& Engineering Aspects, 2005, 265(1-3):141-148.

[20] J Z, M L, H Y, et al. Adsorption properties and mechanism of orthophosphate adsorption on soils from the Yeyahu Wetland of Beijing . [J]. Journal of Beijing Forestry University, 2013, 35(2):118-124.

[21] P E, O A M, D S, et al. Adsorption of $\mathrm{Cu}^{2+}$ and $\mathrm{Pb}^{2+}$ ion on dolomite powder[J]. Journal of Hazardous Materials, 2009, 167(1-3):1044-1049.

[22] K A G, I-T E, A W Y, et al. Effects of $\mathrm{Ca}^{2+}$ on supramolecular aggregation of natural organic matter in aqueous solutions: A comparison of molecular modeling approaches[J]. Geoderma, 2011, 169:27-32.

[23] K M, E R H, G H H. Cation Exchange Capacity and Composition of Soluble Soil Organic Matter Fractions[J]. Soil Science Society of America Journal, 2008, 72(5):1278-1285. 